\title{
اللار اســــــــــــــات
}

\section{البناء المعرفي لعلم المعلومات : دراسة تأصيلية وخريطة معرفية مقترحة}

د. رضا محمد محمود التجار

أستاذ المكتبات و المعلومات المساعد مدود

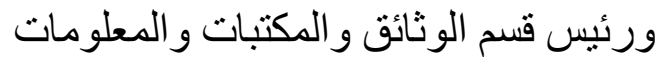

كلية اللغة العربية بالمنوفية- جامعة الأز هر

redaelnagar@yahoo.com

مستخلص:

تتناول الدراسة البناء المعرفي و الإطار الفكري لعلم المعلومات؛ وتهدف إلى التعرف على سمات وخصائص علم المعلومات والملامح العامة لهذا العلم، قدم الباحث فيها تصورين: الأول يوضح الإطار الفكري لعلم المعلومات؛ يتكون من أربعة محاور (دراسات علم المعلوماتـ

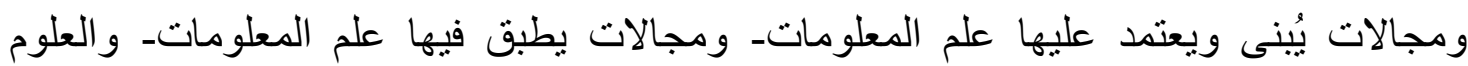
و المجالات التي تتداخل وترتبط بعلم المعلومات)، و الثاني تصور مقترح لخريطة معرفية لعلم المعلومات من وجهة نظر الباحث.

/ / مهيد:

علم المعلومات مجال متعدد الارتباطات و العلاقات، يهتم بدر اسة إنتاج المعلومات وتنظيمها و اختز انها واسترجاعها وبثها واستخدامها، استخدم هذا المصطلح منذ ستينيات القرن الماضي للإشارة إلى الإفادة من المعلومات واستثمار التقنيات الحديثة، وهو جزء هن مجاء مجال تطبيق العلوم

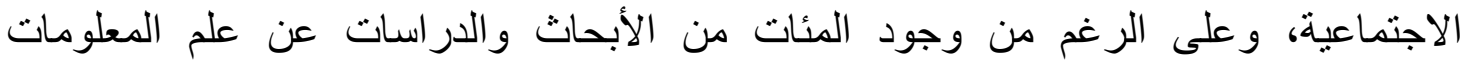
وتعريفاته، لم يصل كل ذلك النتاج الفكري إلى تقديم تعريف متفق عليه بين جمهور الباحثين، فهنالك مالا يقل عن . . . أتعريف حتى الآن لعلم المعلومات، إلا أن علماء المعلومات اتفقو ا على أن مجالهم متداخل Interdisciplinary، ومرتبط بعلوم أخرى، وعلى الجانب الآخر ييشر لآل 
البعض بزوال وانتهاء علم المعلومات، ويحاول الباحث في هذه الدراسة أن يستكثف محاور

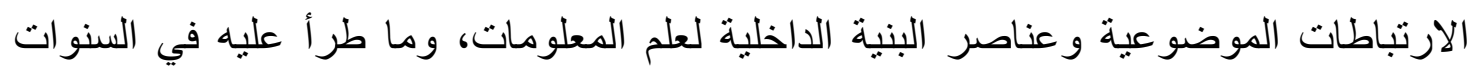

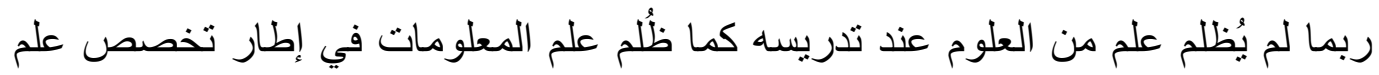

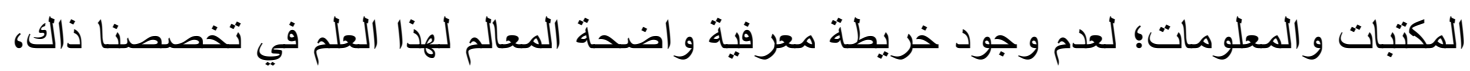

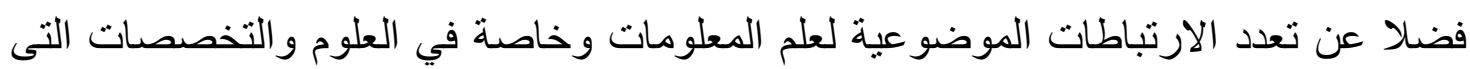

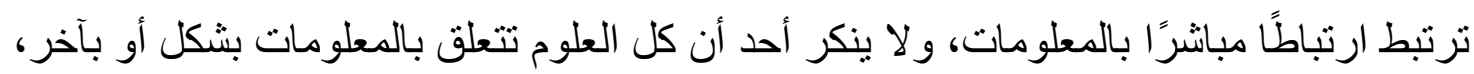

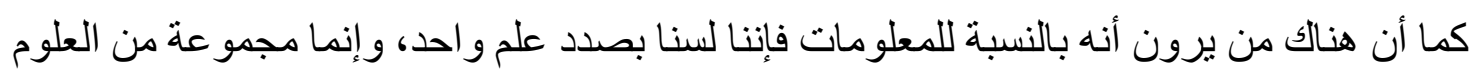

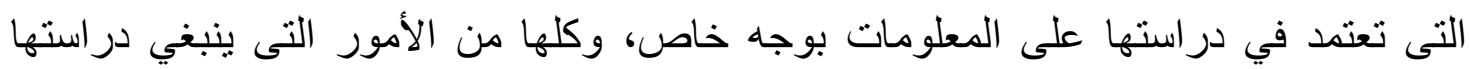

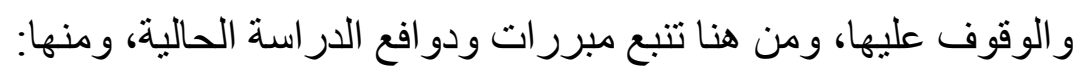

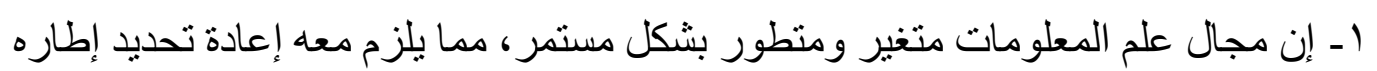

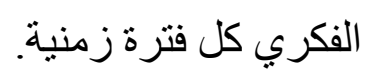

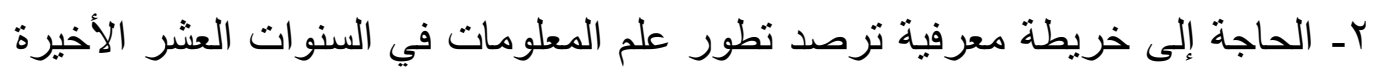

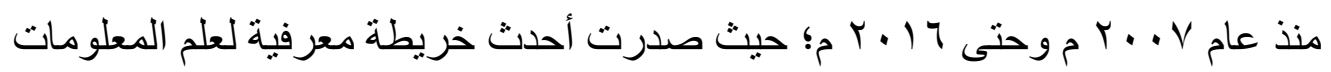

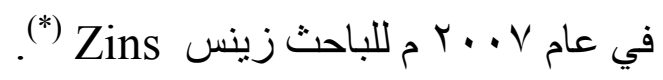

r/l r r r أهداف الدراسة:

تسعى الدراسة إلى تحقيق مجمو عة من الأهداف الرئيسة، ومنها :

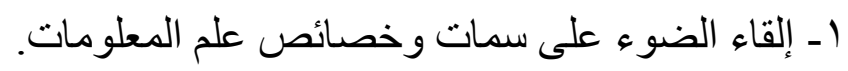

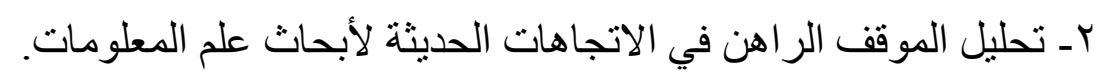

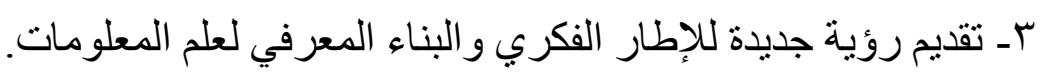

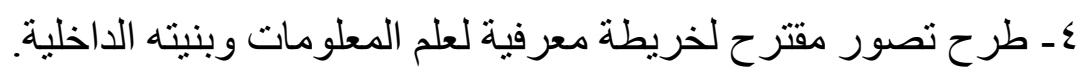

(*) Zins, Chain. " Knowledge Map of Information Science".- Journal of The American Society for Information Science and Technology ,v.58, no .4 ( 2007) pp.526-535. 


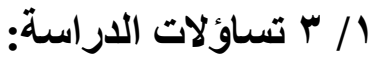

$$
\begin{aligned}
& \text { تحاول الدر اسة الإجابة عن التساؤلات الآتية: } \\
& \text { ـ ـ ما السمات و الخصائص الرئيسة لعلم المعلومات؟ }
\end{aligned}
$$

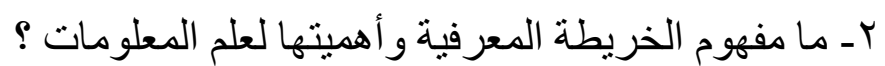

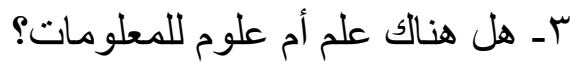

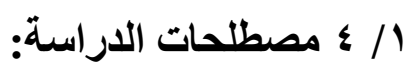

أـ خر ائط المفاهيم Concepts Map: رسوم تخطيطية توضح العلاقات المتبادلة بين

$$
\text { المفاهيم والتي تمثل الأطر الفكرية لمجال من مجالات المعرفة. }
$$

ب - خرائط المعرفة Knowledge Map: عبارة عن خريطة مفاهيم Concepts: Map أو شبكة من المفاهيم Network of Concepts لتكوين صورة عن مجال

$$
\text { موضو عي أو معرفي محدد من مجالات المعرفة البشرية. }
$$

وفقًا للأهداف المرسومة للار اسة؛ فإن المنهج المناسب لها هو المنهج الوصفي التحليلي

$$
\text { / / م منهج البحث: }
$$

الذي يعتمد على أسلوب: المسح، والوصف، والتحليل للظاهرة موضوع الدراسة، من خلال

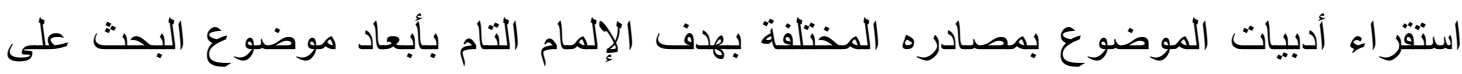

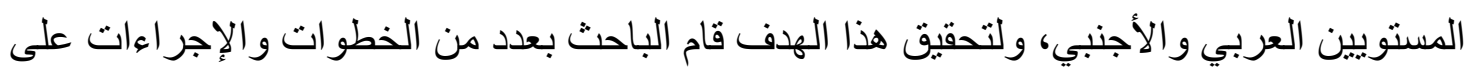
النحو التالي : النين

أولا: الاطلاع على ما كتب باللغة العربية والأجنبية عن علم المعلومات وبخاصة الخرائط

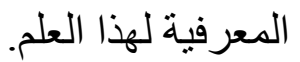
ثانيا: البحث في قو اعد البيانات العالمية المتاحة من خلال بو ابة المجلس الأعلى للجامعات، أو المتاحة من خلال بنك المعرفة المصري.

/ / 7 مراجعة الإنتاج الفكري:

تبين من خلال البحث في قو اعد البيانات ومحركات البحث العامة و المتخصصة، فضلات عن البحن مراجعة الإنتاج الفكري المطبوع، وجود بعض الدراسات وبخاصة الأجنبية منها، تتفق مع

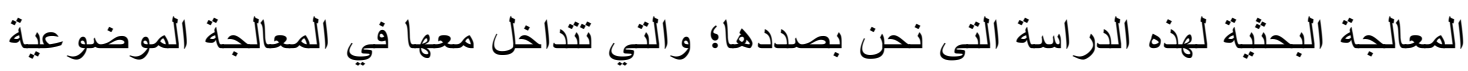
العامة والمنهجية. أما بقية الدراسات التى أفاد منها الباحث في صياغته و عرضه فنه فوف يتم استعر اضها في سياق البحث وفقًا لأهداف الدراسة الحالية، ويمكن تقسيم هذه الدراسات إلى لى محورين أساسيين: المحور الأول: الدراسات التى تناولت الارتباطات الموضوعية لعلم المعلومات، و التي سوف يتم تناولها على النحو الآتي: 


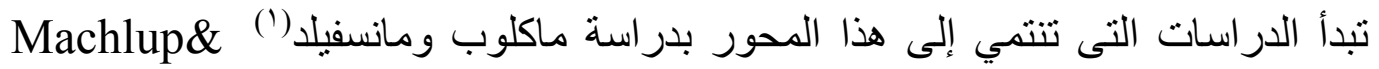
Mansfield The study of Information: Interdisciplinary Messages

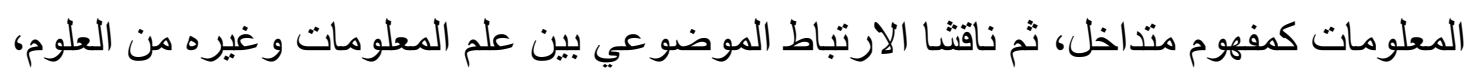

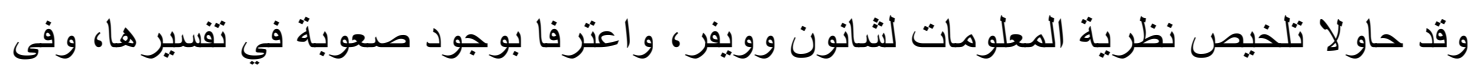
النهاية أكد ماكلوب على أن المعلومات ظاهرة إنسانية.

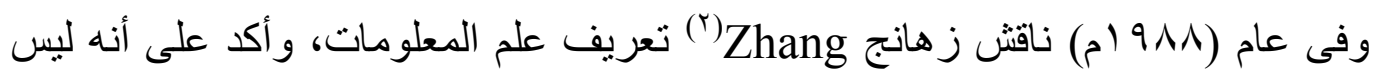

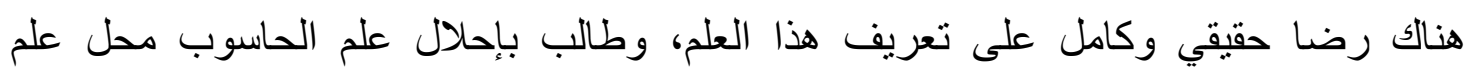

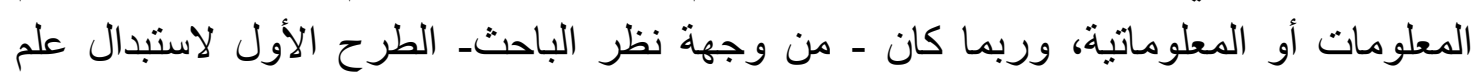

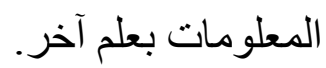

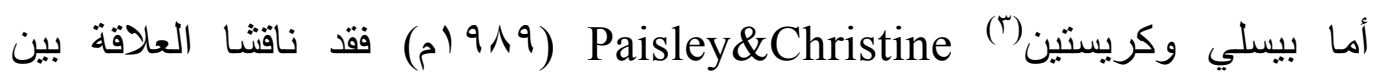
الاتصالات و التحليل البيليو متري وخريطة البحث العلمي، وبعدهما كتبت كريستين بورجمان بحثنا

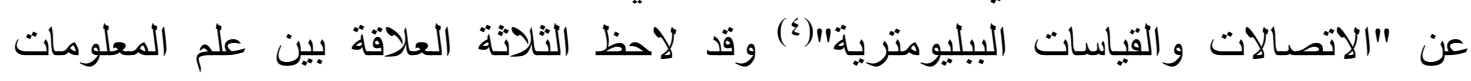
و الاتصالات، و أيضًا التداخل بين علم المعلومات وتقائنيات الاتصالات مثل البريد الإلكتروني ونظم استرجاع المعلومات.

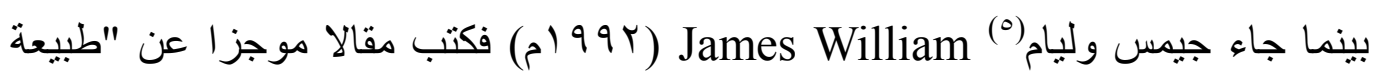

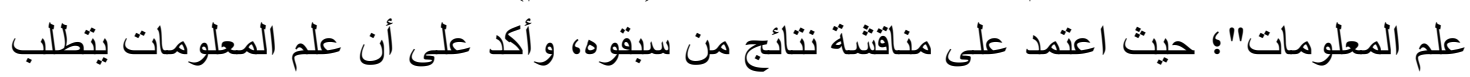

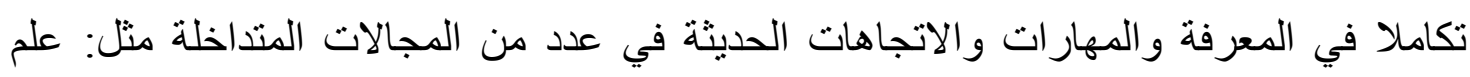

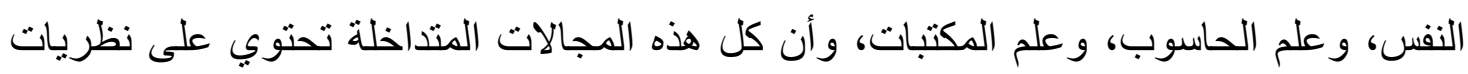

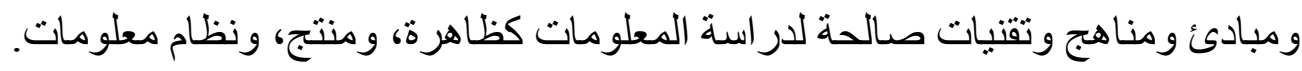

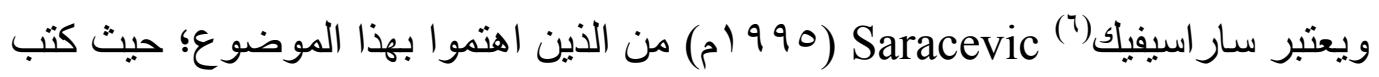

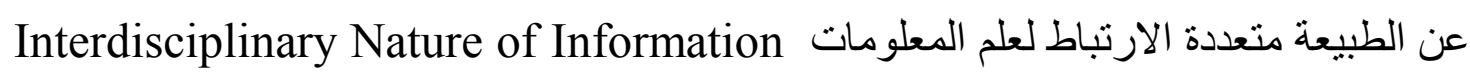

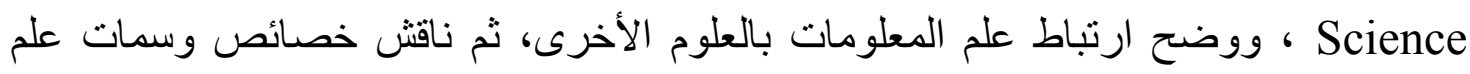

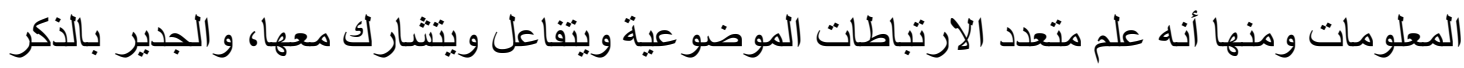

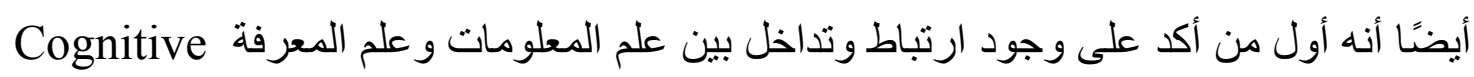
Science

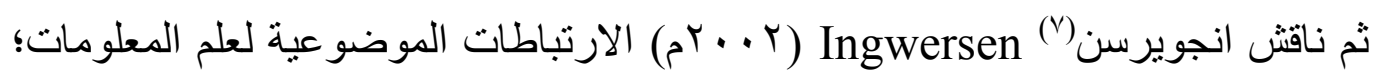

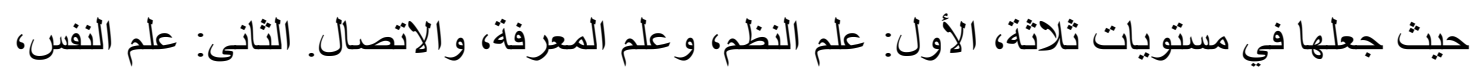


اللغويات، و علم الاجتماع. الثالث: المجالات التطبيقية (المكتباتـ التوثيق).

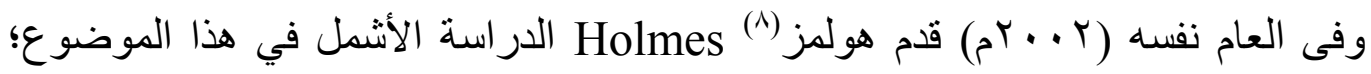
و هى عبارة عن رسالته الأكاديمية للحصول على الدكتور اه في جامعة أونتاريو في لندن، بحث فيها نشأة علم المعلومات وتطوره وبداياته التاريخية، وفيها قدم عرضًا لجهود الباحثين الذين ناقشو ا ارتباط وتداخل علم المعلومات بالعلوم الأخرى.

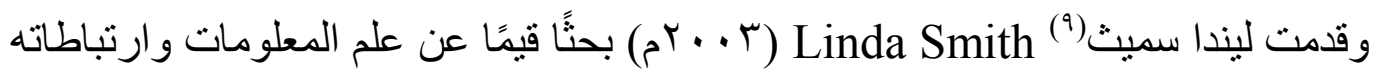
الموضوعية، استعرضت فيه بعض الدراسات التى تناولت الارتباطات الموضوعية لعلم المعلومات مثل: در اسات شير ا، وماكلوب، وكو اديك وغير هم، وتحدثت عن دور علم الحاسوب بله

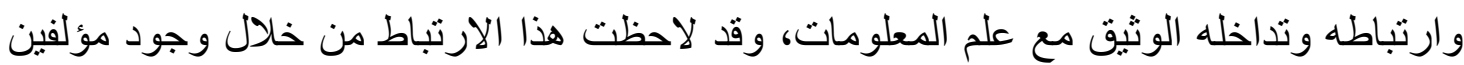
ومتخصصين في علم الحاسوب من خلال فحص وتحليل مقالات مجلة الجمعية الأمريكية لعلم المعلومات (JASIS) و أكدت من خلال در استها على إسهامات علماء الحاسوب في مجالات دقيقة

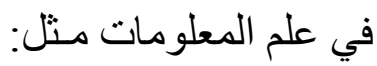

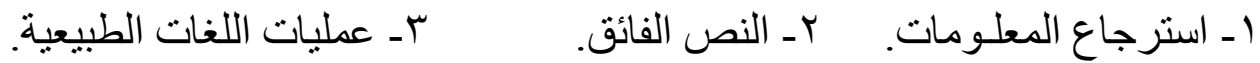

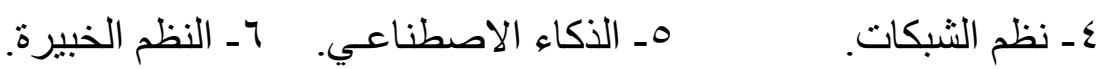

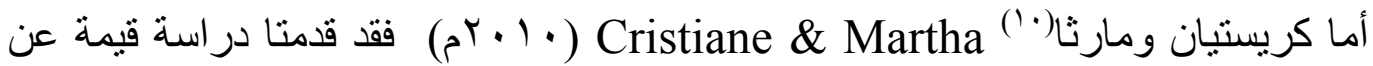
الارتباط الموضوعي لعلم المعلومات بالعلوم الأخرى، وناقشتا خر ائط المفاهيم كأداة من أدوات المعرفة، وقدمتا تصورًا لخر ائط مفاهيم Conceptual Maps علم المعلومات.

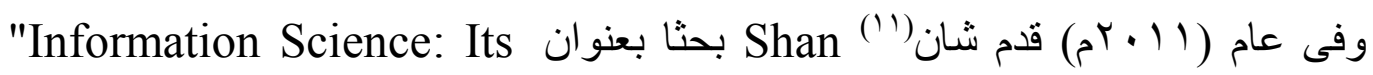
تناول فيه استعر اض البدايات التاريخية لعلم المعلومات Past, Present and Future" و مر احل تطور هذا العلم، ثم أفرد جانبًا من بحثه للحديث عن المجالات المرتبطة بالمعلومات؛ وقد حصر ها في قائمة تتضمن ST RT مجالا منها على سبيل المثال (المعلومات الزر اعيةـ نظرية معلومات الحاسوبـ معلومات الأرشيفــ نظرية المعلومات الأرشيفيةــ المعلومات الدلاليةـ المعلوماتيةـ المعلومات البيولوجيةـ المعلومات الطبيةـ نظرية الجزئيات). وقدم مايكل بوكلاند(r'Michael Buckland (r ( • (Yم) مقالا ناقش فيه العلوم المرتبطة بالمعلومات، فضلا عن ارتباط علم المعلومات بالعلوم الأخرى والاستخدامات المختلفة للعلم،

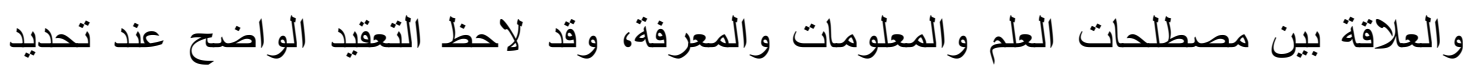
مجالات وحدود علم المعلومات بدقة، و أكد على ارتباط علم المعلومات بعدد من العلوم مثل: علم

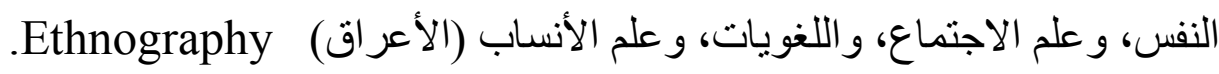


المحور الثاني: الدراسات التي عالجت البنية الداخلية ( الخريطة المعرفية) لعلم المعلومات،

$$
\text { وسوف يتم استعر اضها على النحو الآتي: }
$$

تأتى في مقدمة الدراسات التى تناولت البنية المعرفية لعلم المعلومات الدراسة التهى التى قدمها

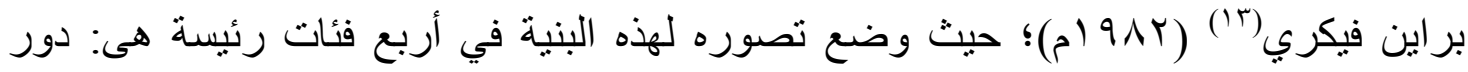
المعلومات في المجتمع، و الحواسيب الإلكترونية و الاتصالات، و نظم المعلومات، ومناهج البحث في علم المعلومات. وفى عام (9100 (م) قدم بلاك Blake تصوره للمجالات الأساسية في علم

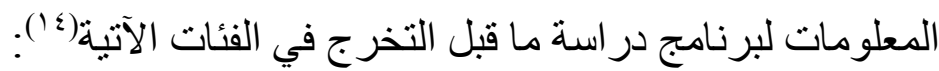

$$
\text { 1 ـ أساسيات علم المعلومات. }
$$

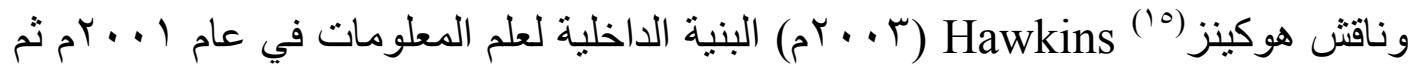
عدلها في عام r . . rم، وقد هدف من بحثه إلى وضع تعريف جديد لعلم المعلومات، وتكوين

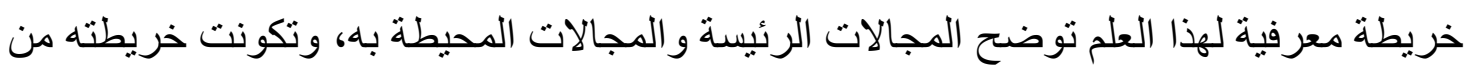

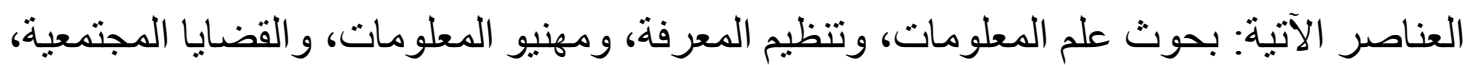

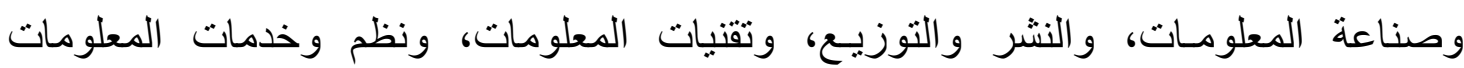

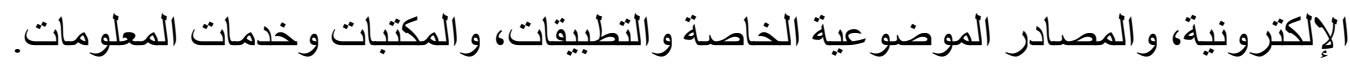
ويعتبر عام (V . . . م) هو أكثر الأعو ام بحثًا ومناقشة لهذا الموضوع، ففي هذا العام صدرت

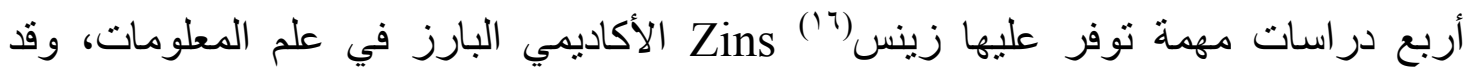
صدرت هذه الأعمال في شكل سلسلة تتناول علم المعلومات ومكو ناته بشكل عام فيما يأتي:

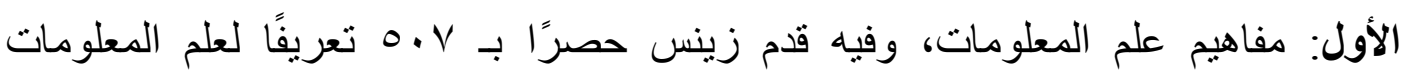
و النظريات المرتبطة به، وتعريف المجال بشكل عام. الثانى: تناول تعريف " البيانات، و المعلومات، و المعرفة، و الرسالة" قدم من خلالها زينس ما بـان

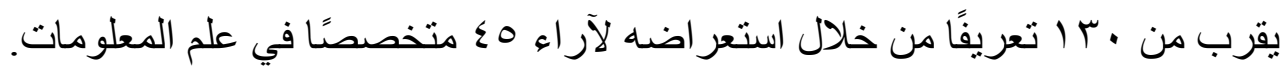
Knowledge Map of Information Science الثالث: خريطة معرفية لعلم المعلومات ؛ حيث قدم خريطة معرفية مقترحة لعلم المعلومات. الرابع: جداول تصنيف علم المعلومات Classification Schemes of Information Science، استعرض فيها آراء وجهود ^r متخصصًا في علم المعلومات، والجدير بالذكر أن

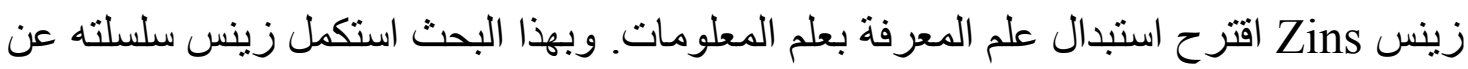
علم المعلومات، وتجدر الإشارة إلى أن هذه الآراء التى قدمها زينس لاقت ردودًا و انعكاسات و واسعة من قبل المتخصصين في علم المعلومات بشكل عام، وتم نشر هذه الردود فيما بعد في 
دورية (1') Brazilian Journal

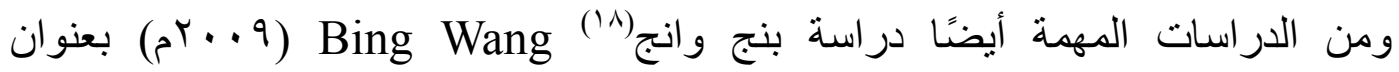
"Information Science: Territory and Relation to Computing Disciplines" تناول فيها طبيعة علم المعلومات كعلم مرتبط بالعلوم الأخرى، وأكد على أن جزء من الصعوبة

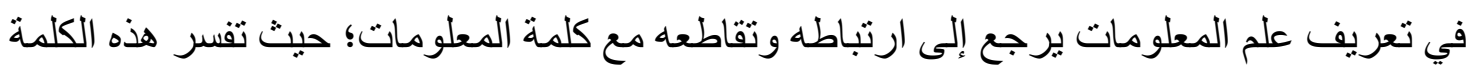

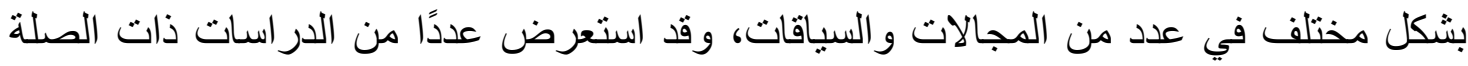

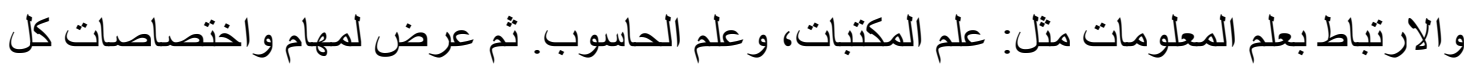
من اختصاصي المعلومات واختصاصي ملمي الحاسوب.

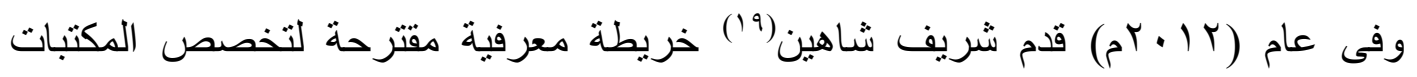

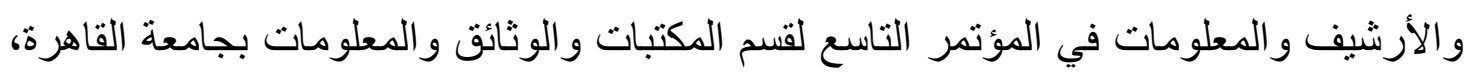

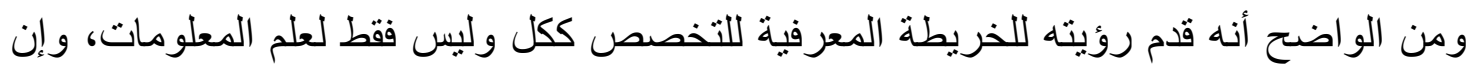

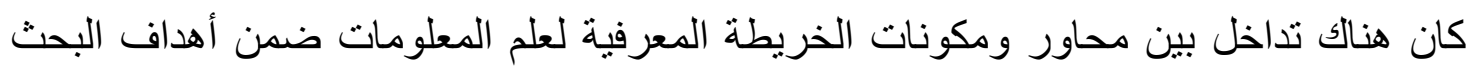
الحالي.

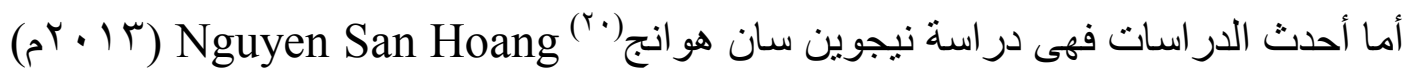

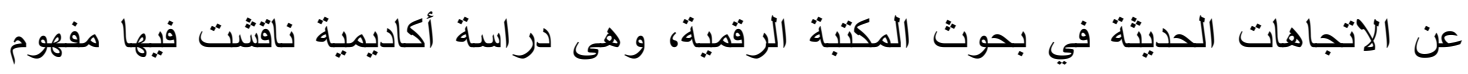

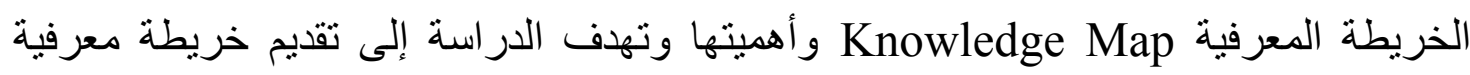

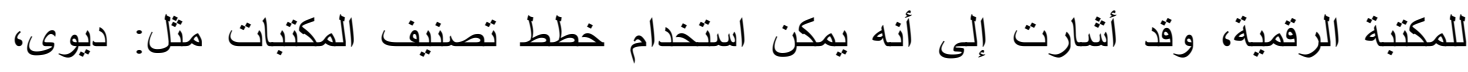

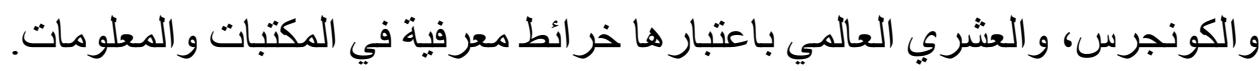

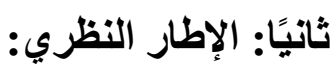

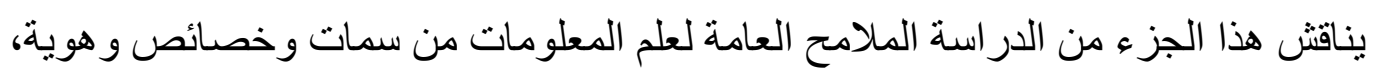

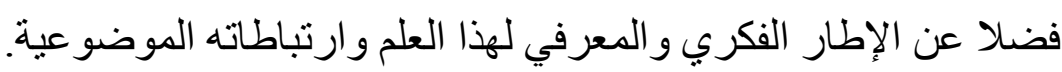

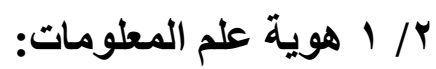

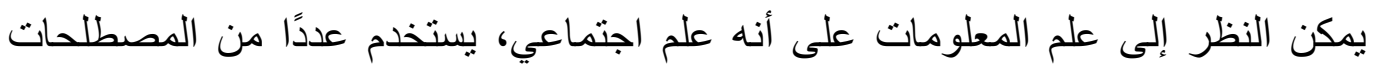

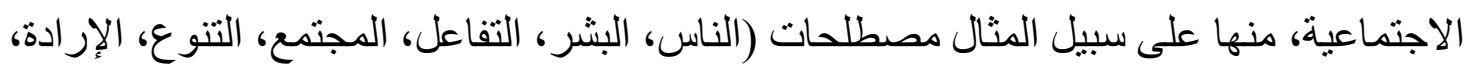

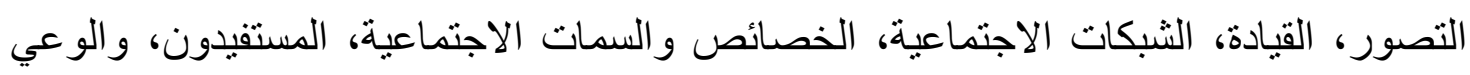

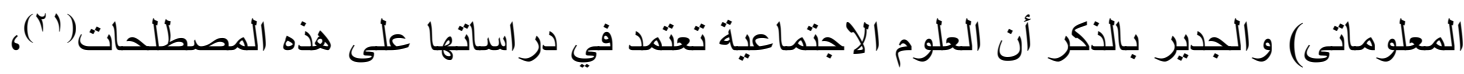

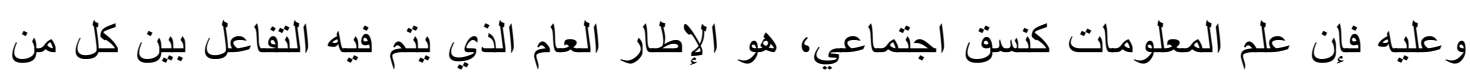

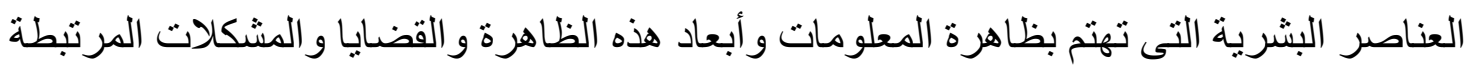




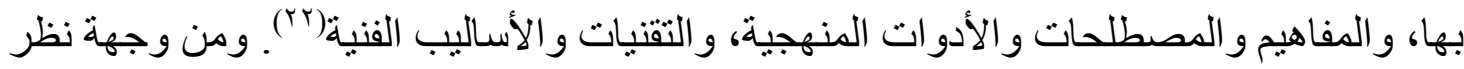

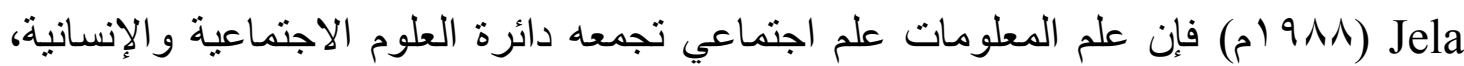

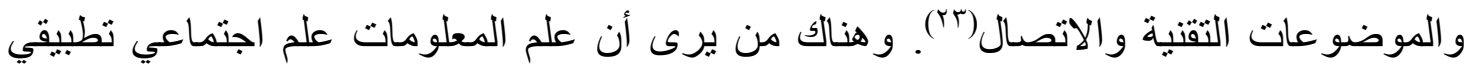
Evelyn Orrico ( Social Applied Science علم المعلومات أحد مجالات تطبيق العلوم الاجتماعية. Y/Y خصائص وسمات ومراحل تطور علم المعلومات:

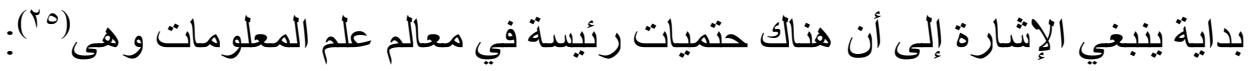
اـ الحتمية التقنية Technological Determinism: حيث يرتبط علم المعلومات التبات ارتباطًا وثثقًا بتقنيات المعلومات Information Technology بشكل عام، وتعتبر جزءً رئيسا

$$
\text { في تطوره ونموه. }
$$

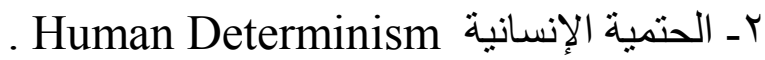
بـ الحتمية الاجتماعية Social Determinism : فعلم المعلومات له بعدانة الهانية أساسيان: البعد

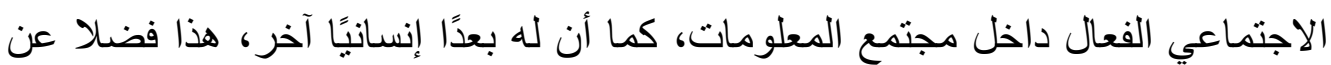

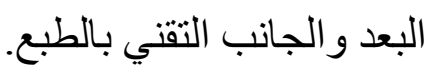

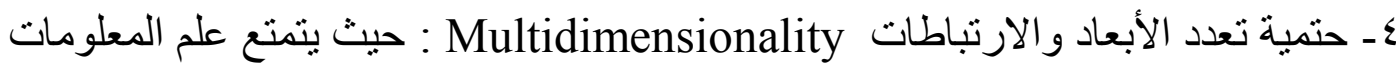

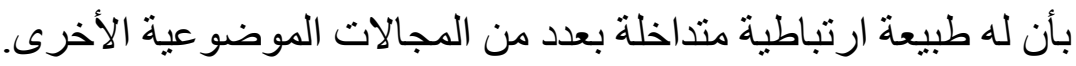

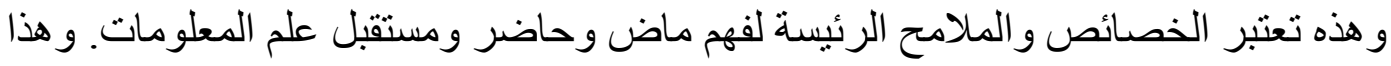

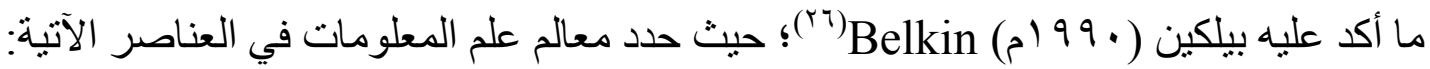
1 ـ نقل المعلومات عن طريق الإنسان (نظم الاتصال المعرفي)

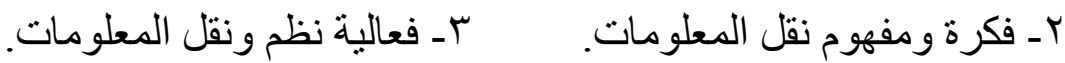

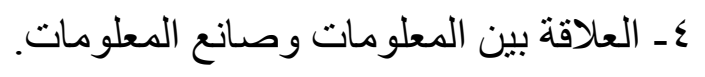
هـ العلاقة بين المعلومات و المستقيدين منها.

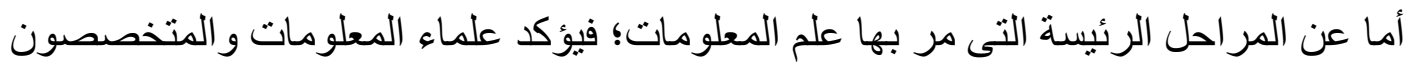

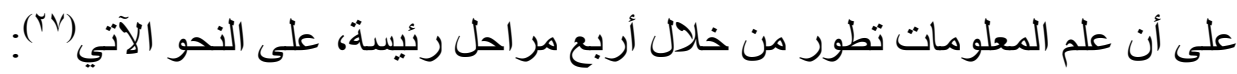

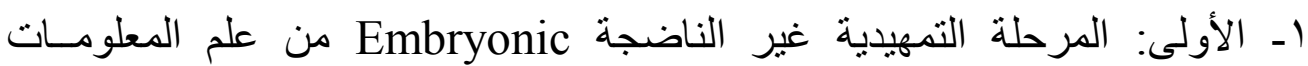

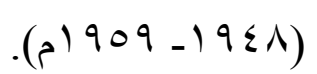

r الثانية: مرحلة التعايش Coexistence في ثلاث حلقات كلاسيكية لعلم المطلومات

$$
\text { (19V - (1909) }
$$

rـ الثالثة: مرحلة الازدهار Prosperity و النمو في قطاع المعلوماتية Informatics 


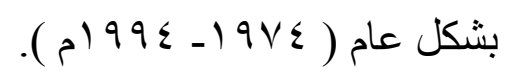

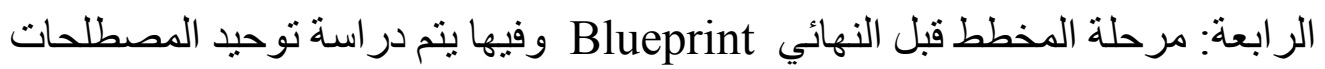

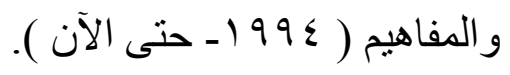

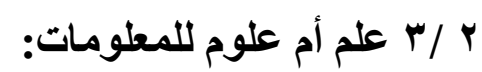

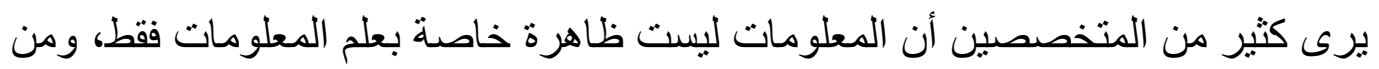
جهة أخرى يؤكد ديبونز (9V0 (م) أن المشكلة ليست في تحديد العلوم التى يمكن ضمها لمجال المعلومات، و إنما في بيان العلوم التى يجب استبعادها من منطلق أن كل العلوم تتعلق بالمعلومات

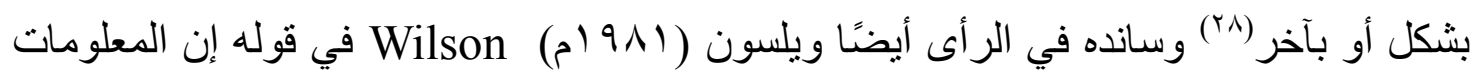

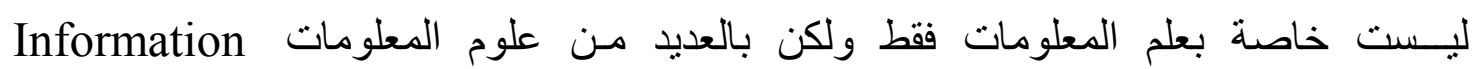

$\left({ }^{\left({ }^{9}\right)}\right.$ Sciences

وبناء على الآراء السابقة سارع بعض المتخصصين إلى اعتبار أن علم المعلومات ليس كافيًا ومعبرًا عن التشارك المعلوماتى للعلوم و المجالات و التخصصات المرتبطة و المنشنابكة في دراسة ظاهرة المعلومات بشكل عام، الأمر الذي جعل البعض يبادر بالدعوة إلى انشطار علم المعلومات إلى علوم مختلفة وتخصصات متنوعة؛ حيث جعلوا علم معلومات في كل العلوم، فظهرت مصطلحات مختلفة دالة على علوم المعلومات، منها على سبيل المثال:

$$
\begin{aligned}
& \text { ا ـ علم المعلومات الزر اعي. } \\
& \text { r ـ ـ علم المعلومات الطبي. } \\
& \text { r - علم المعلومات البيولوجي. } \\
& \text { ـ ـ علم المعلومات الاجتماعي أو علم الاجتماع المعلوماتي. } \\
& \text { هـ علم المعلومات الاقتصسادي أو علم الاقتصساد المعلوماتي. }
\end{aligned}
$$

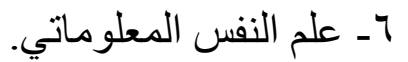

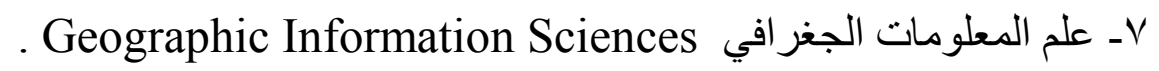

و الجدير بالذكر أنه تم إسقاط الخصائص الرئيسة لعلم المعلومات على هذه النماذج السابق

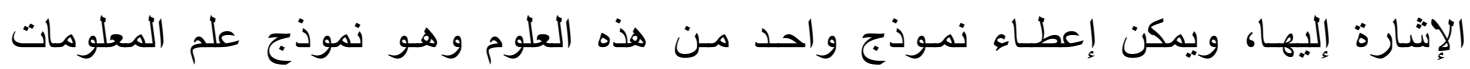

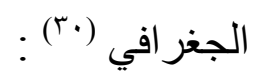




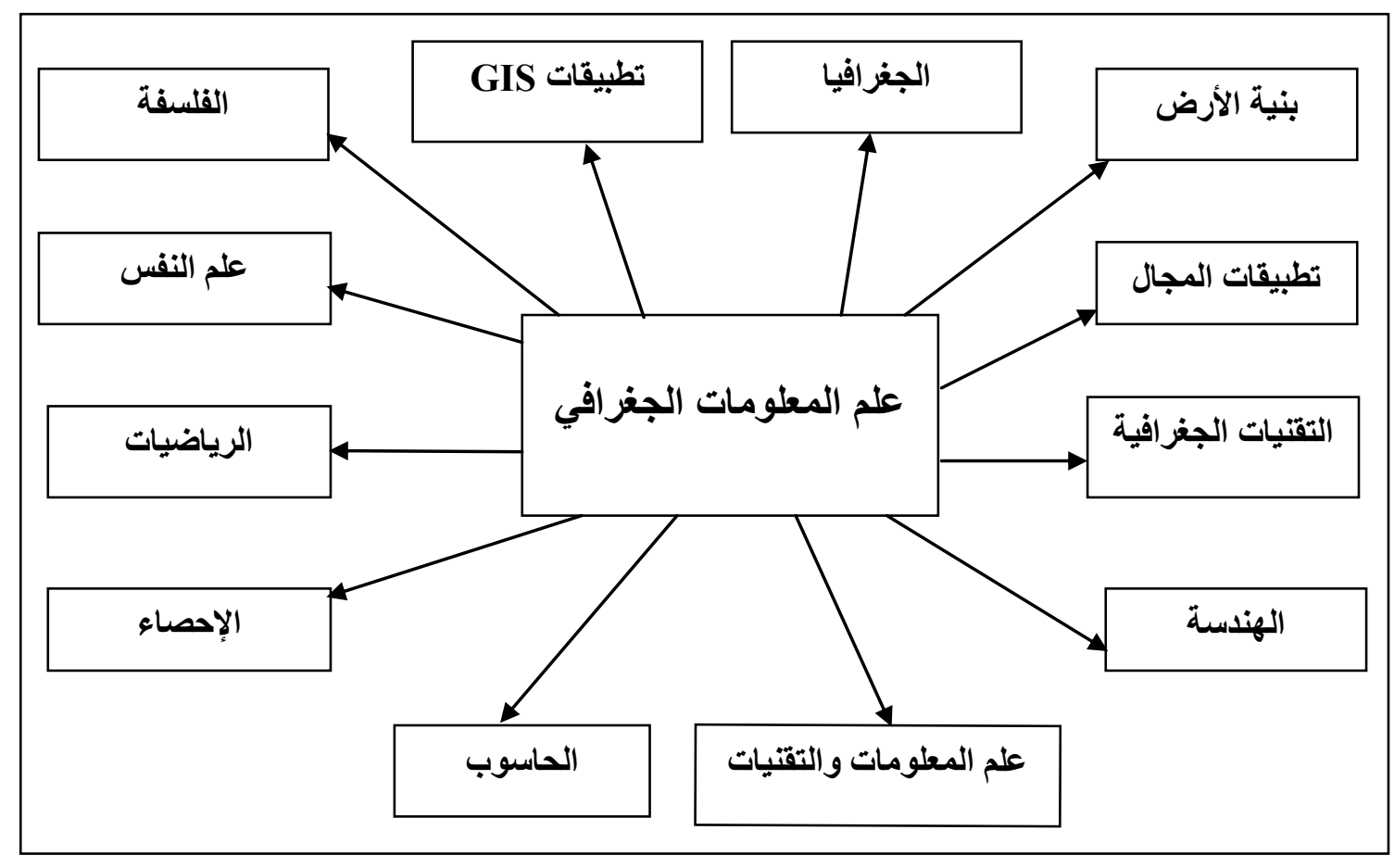

شكل رقم ( ) يوضح مجال علم المعلومات الجغرافي

وبالنظر إلى الشكل السابق يمكن الخروج بعدد من الملاحظات كما يأتي:

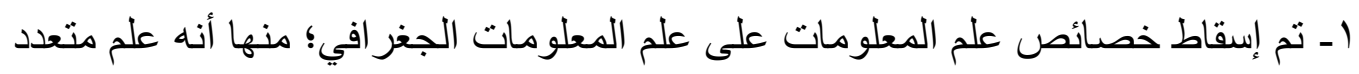

الارتباطات والتخصصات الموضوعية، كما يظهر من ارتباط علم المعلومات الجغر افي بالهندسة والفلسفة والرياضيات و الإحصاء و علم الحاسوب و الهندسة، ومنها

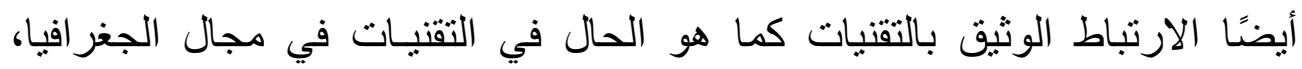

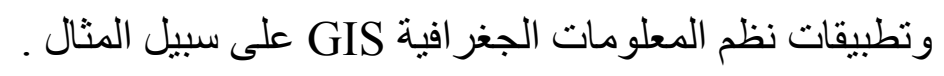

r- يظهر الثكل الارتباط الوثيق بين علم المعلومات و التقنيات من جهة و علم المعلومات

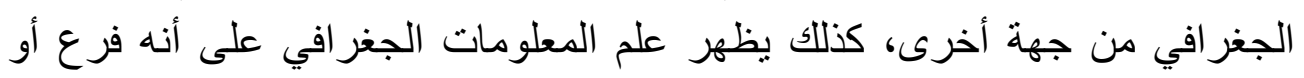
تطبيق لعلم المعلومات كعلم أم في هذا الثأن كما يبدو.

ويرى الباحث أن هذا الإسقاط والانشطار ليس له مبرر، مع الاعتر اف والتأكيد على أن

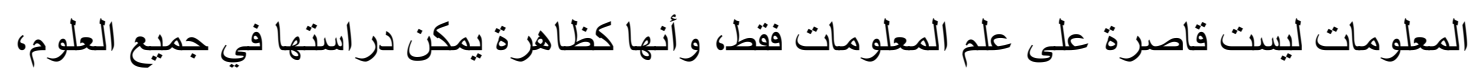
بل و إنها تعتبر العامل المشترك بين جميع العلوم بشكل عام، ويؤكد الباحث أن علم المعلومات هو علم و احد رئيس لله مناهجه وخو اصه وسماته الرئيسة، وله أركانه العلمية الرصينة التى بنبغي

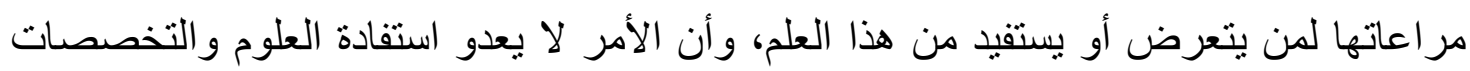




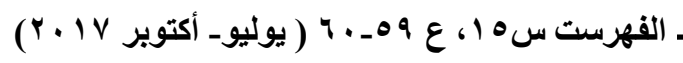

الأخرى من المعلومات كظاهرة مشتركة بين التخصصات العلمية المختلفة، ولا يبرر ذلك إدعاء

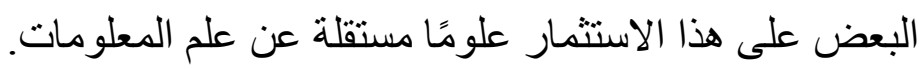

ץ/ ع الخـط الزمــي Time Line للارســات الـتي ناقشت الارتباطـات الموضـوعية لعـم

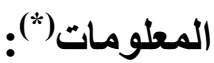

ينظر البعض إلى علم المعلومـات بوصفه علمًا غير عـادى Science Super، أو العلم السند، أو ما ور اء العلم Meta Science، وربما كانت هذه النظرة إلى علم المعلومـات هي مـا فيا جعل شير ا Shera (9VY ( م) يعرف علم المعلومات من خلال ارتباطه بالعلوم الأخرى بأنه علم

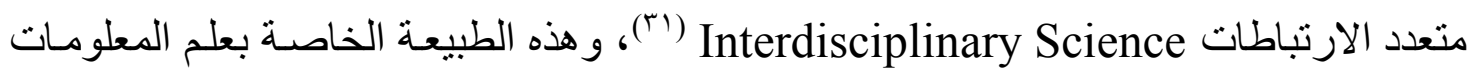

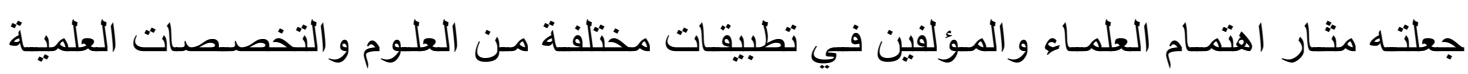

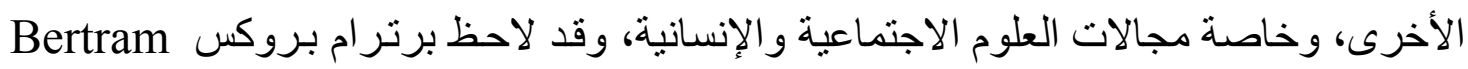

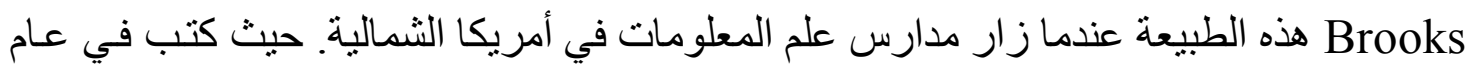

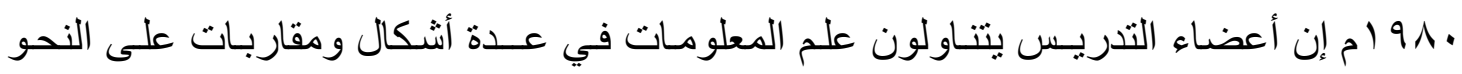

$$
\begin{aligned}
& \text { ا ـ أستاذ (أ) يدرس اللغويات Linguistics في علم المعلومات. } \\
& \text { Yـ أستاذ (ب) يدرس مقررًا يغطى علم الحاسوب لمتخصصى المعلومات. }
\end{aligned}
$$

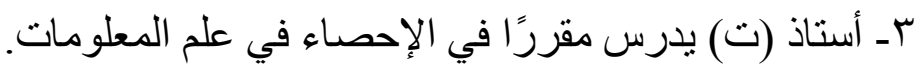

وتساءل عمّن يدرس علم المعلومات، فكانت الإجابة على ذلك عادة بأن علم المعلومات مجـال متداخل من: اللغويات، و الاتصالات، و علم الحاسوب، ومناهج البحث، وفنيات علم المكتبات مثل: التكثيف و التصنيف: منغ منيف.

ويمكن هنـا اسـتعر اض الآر اء المختلفـة للعلمـاء و المتخصـصـين في علـم المعلومـات، و الارتباطات الموضوعية و المجالات العلمية لهذا العلم عبر السنوات الماضية، وتجدر الإشـارة إلى أن هذه الدر اسات قد اعتمدت على تحليل الاستشهادات المرجعية للإنتاج الفكري المتخصص ولهص في علم المعلومات، وخاصة الدوريات المتخصصة و على وجه الدقة هاتين الدوريتين: Annual Review of Information المر اجعة السنوية لعلم المعلومات و التقنبات

Science \&Technologies (ARIS\&T).

(*) يتناول الباحث هنا الدراسات التي ناقثت واستعرضت الارتباطات الموضوعية لعلم المطلومات منذ عام . 190 حتى

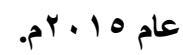


Tournal of American Society of بـ كجـة الجمعيـة الأمريكيـة لعلم المعلومـات Information Science (JASIS).

$$
\begin{aligned}
& \text { تات }
\end{aligned}
$$

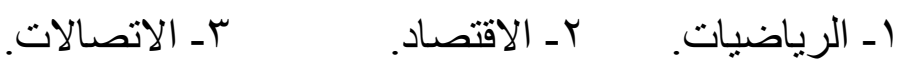

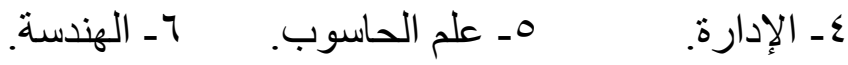

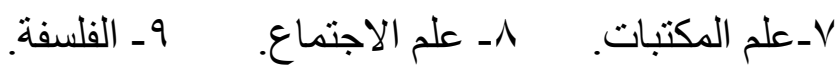

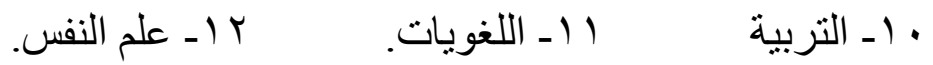

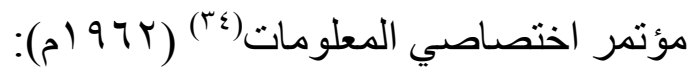

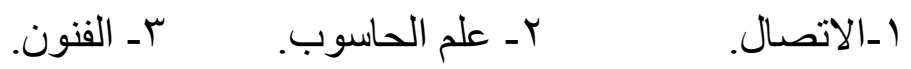

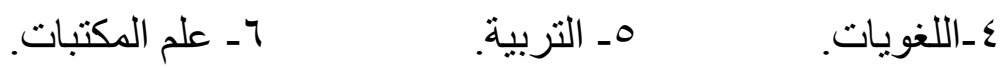

$$
\begin{aligned}
& \text { Vـ المنطق. }
\end{aligned}
$$

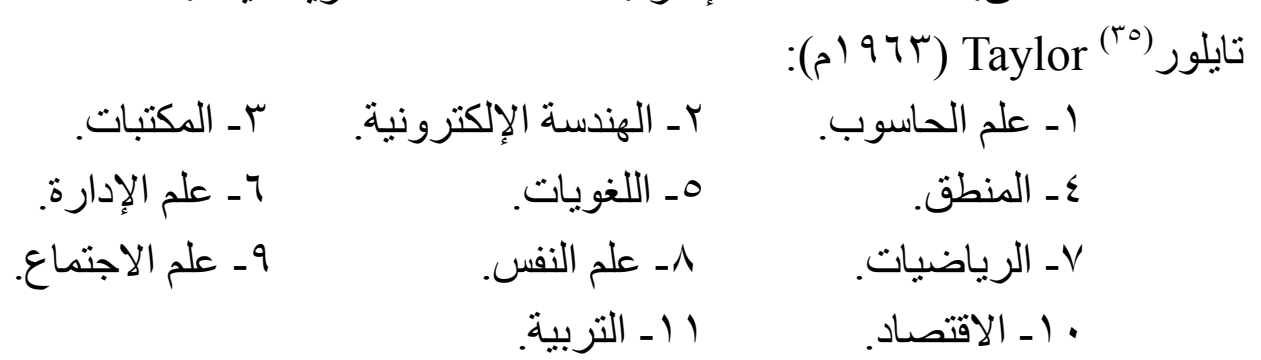

$$
\begin{aligned}
& \text { كودر|(rT) Cudra }
\end{aligned}
$$

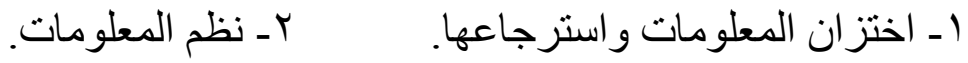

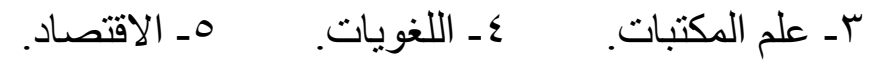

$$
\begin{aligned}
& \text { 7- الهندسة. } \\
& \text { بوركو (rvo Borko }
\end{aligned}
$$

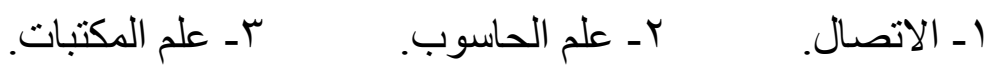

$$
\begin{aligned}
& \text { ع ـ الفنون الرسومية The Graphic Arts } \\
& \text { V- الإدارة. }
\end{aligned}
$$

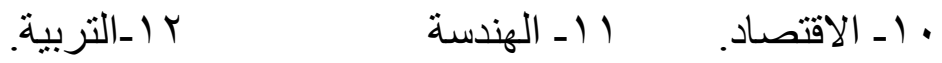

$$
\begin{aligned}
& \text { شير| (r^) }
\end{aligned}
$$

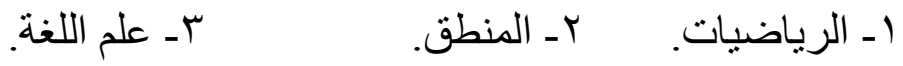

(*) تجدر الإشارة هنا إلى أن دراسة "تات" استعرضت الارتباطات الموضوعية لمجال التوثيق، حيث إن استخدام

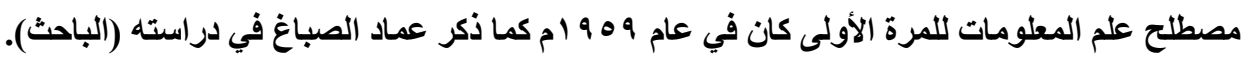




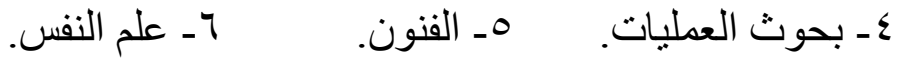

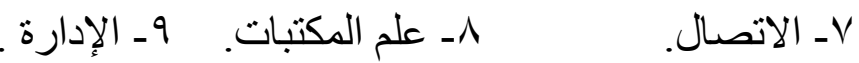

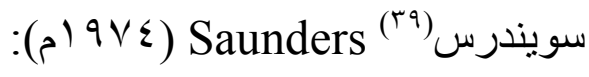

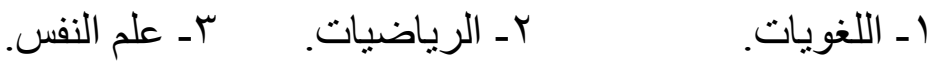

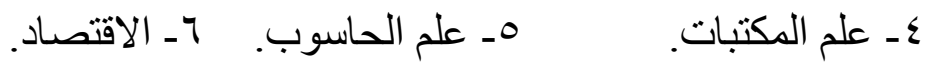

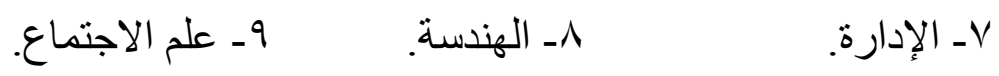

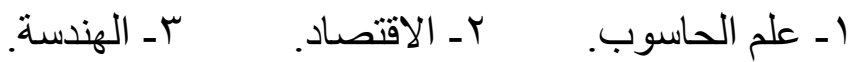

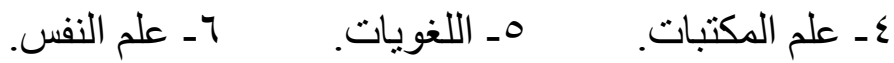

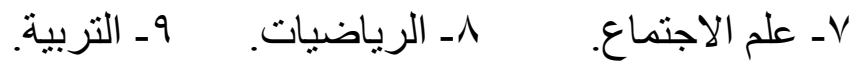

$$
\begin{aligned}
& \text { كاسبر (\&) }
\end{aligned}
$$

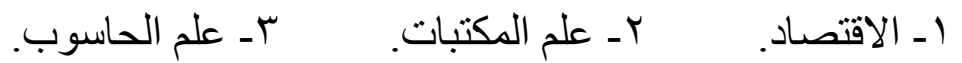

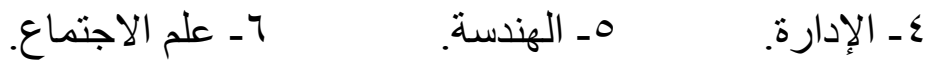

$$
\begin{aligned}
& \text { Vـ التربية. } \\
& \text { ماكلوب(\&) Machlup }
\end{aligned}
$$

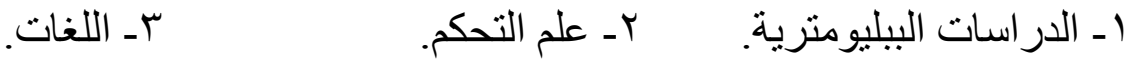

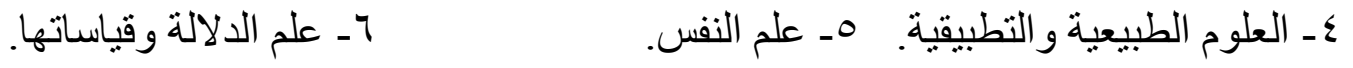

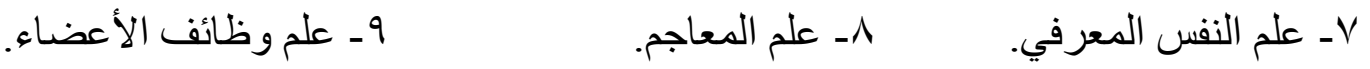

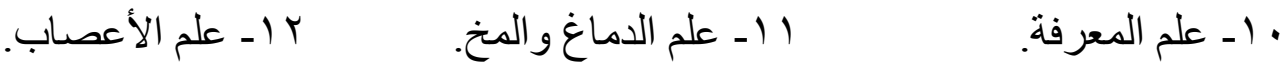

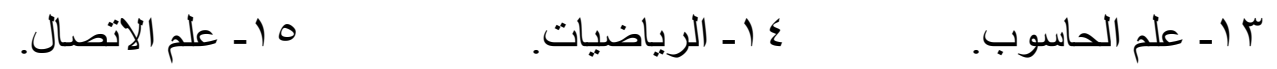

$$
\begin{aligned}
& \text { T ا ـ علم المكتبات. }
\end{aligned}
$$

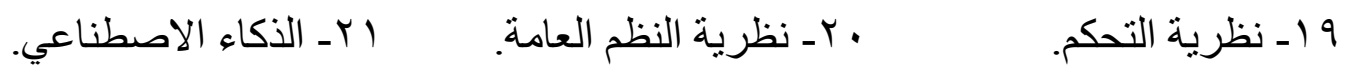

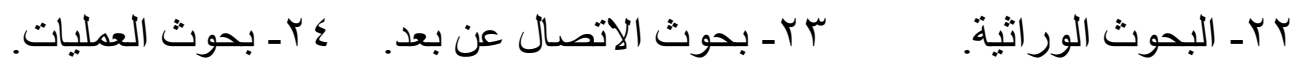

$$
\begin{aligned}
& \text { بوكلاند) Buckland }
\end{aligned}
$$

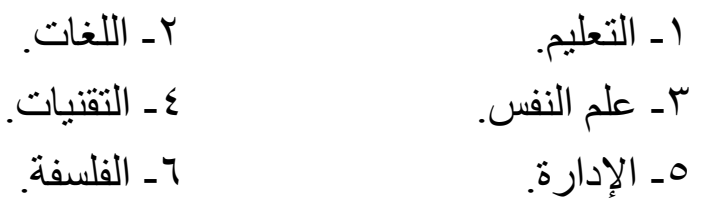

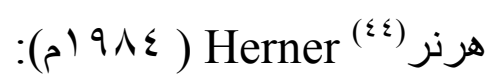

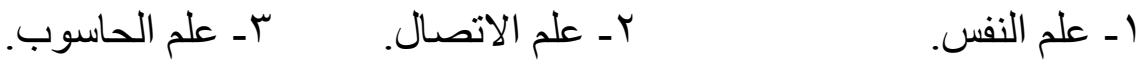

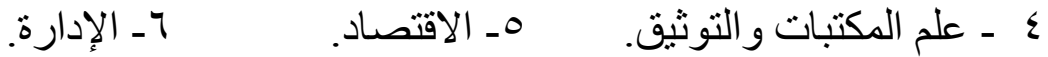




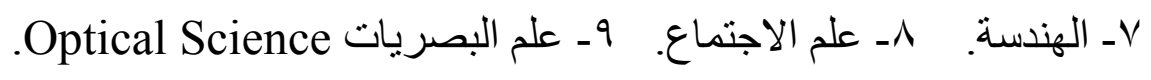

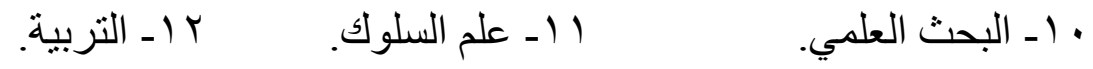

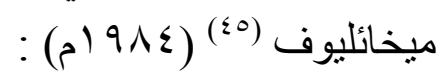

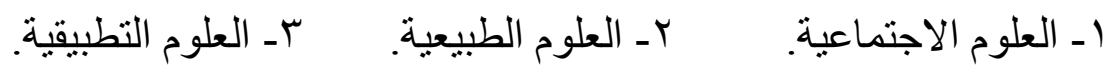

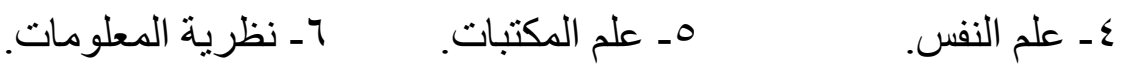

$$
\begin{aligned}
& \text { كو اديك (\$7) }
\end{aligned}
$$

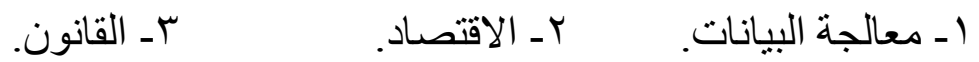

$$
\begin{aligned}
& \text { ع- المنطق. }
\end{aligned}
$$

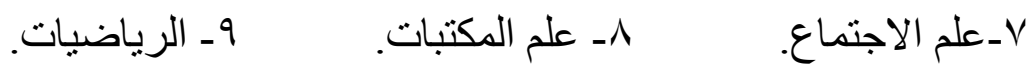

$$
\begin{aligned}
& \text { • 1 إ- علم النفس. }
\end{aligned}
$$

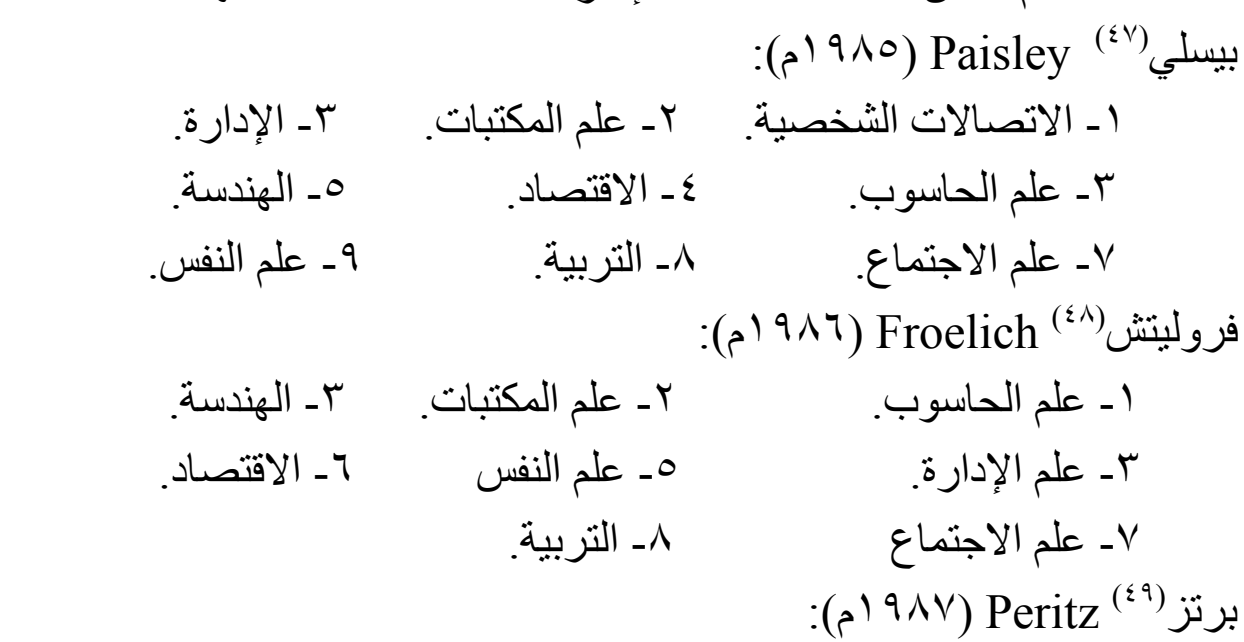

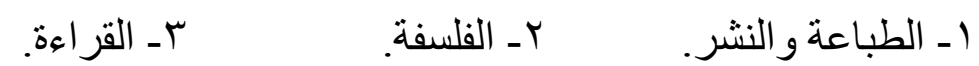

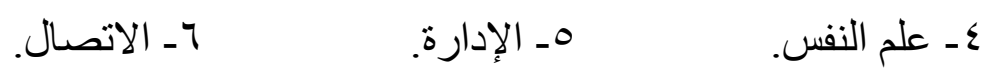

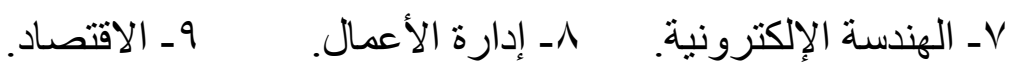

$$
\begin{aligned}
& \text { • 1 اـ السياسة. }
\end{aligned}
$$

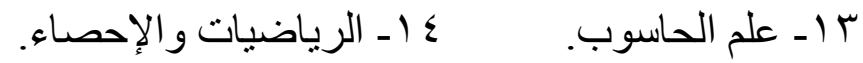

$$
\begin{aligned}
& \text { الصباغ (م) Alsabbagh }{ }^{(0)}
\end{aligned}
$$

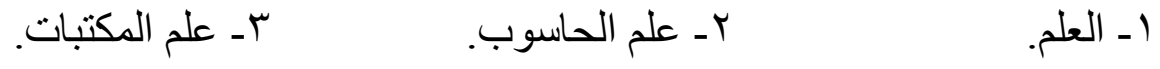

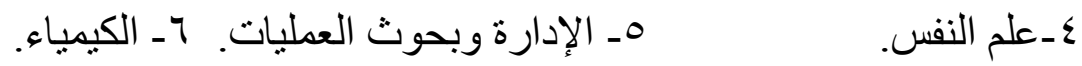

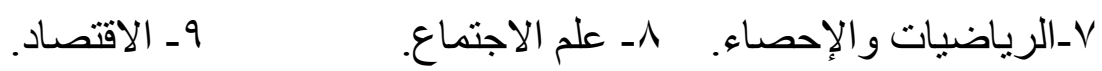

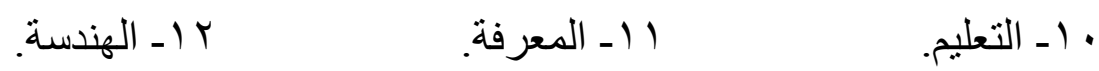

$$
\begin{aligned}
& \text { rا اـ العلوم الطبية. }
\end{aligned}
$$




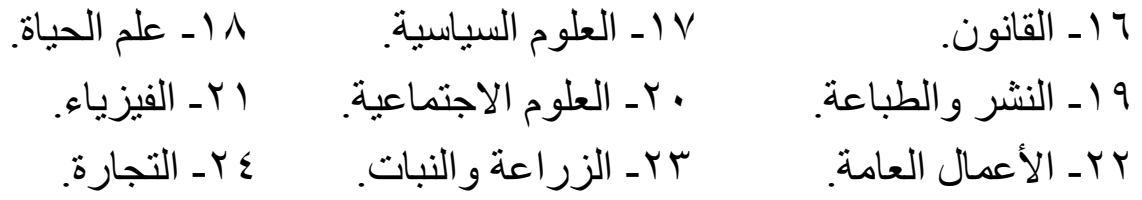

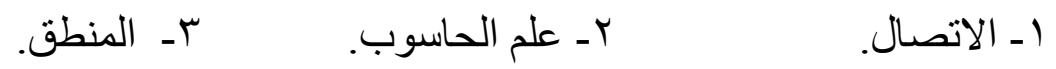

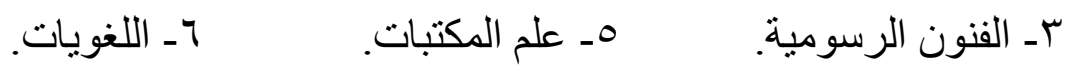

$$
\begin{aligned}
& \text { Vـ الإدارة. } \\
& \text { • 1 الاقتصاد. }
\end{aligned}
$$

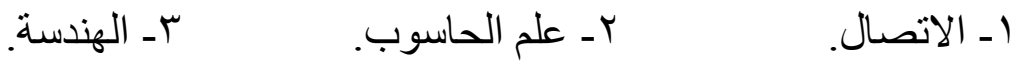

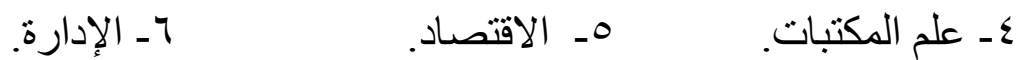

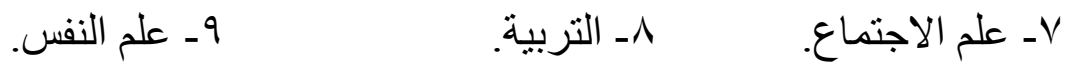

$$
\begin{aligned}
& \text { مارثا ويليامز (or) }
\end{aligned}
$$

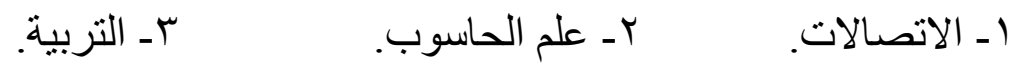

$$
\begin{aligned}
& \text { 7- الإلكترونيات. } \\
& \text { r- الهندسة. } \\
& \text { V- المنطق. }
\end{aligned}
$$

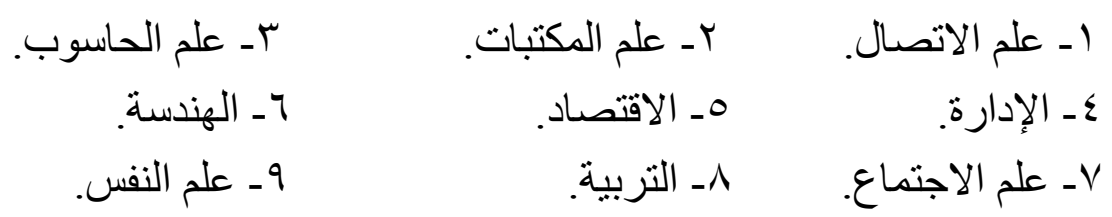

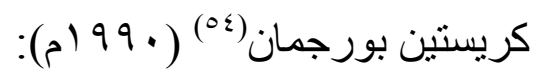

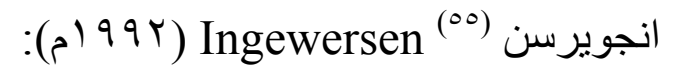

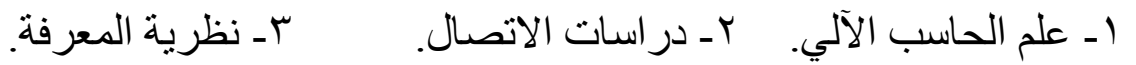

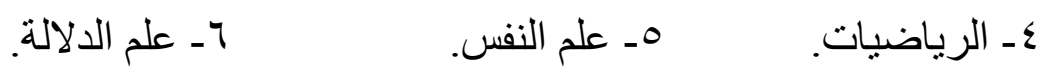

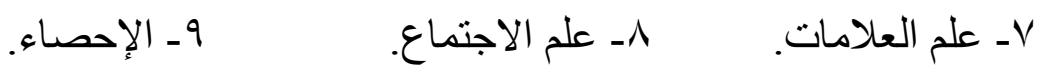$$
\text { رايوارد (07) Rayward }
$$

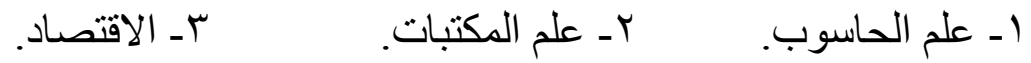

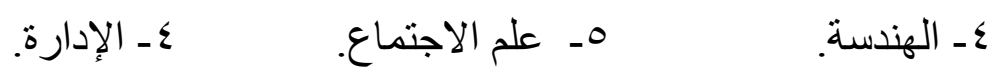$$
\text { Vـ التربية. }
$$

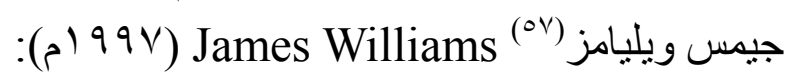

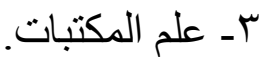
1 ـ علم الحاسوب. 


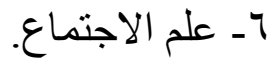

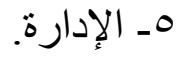

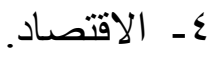

$$
\begin{aligned}
& \text { ^ـ علم النفس. }
\end{aligned}
$$

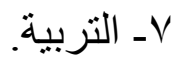

$$
\begin{aligned}
& \text { بوكلاند) Buckland }
\end{aligned}
$$

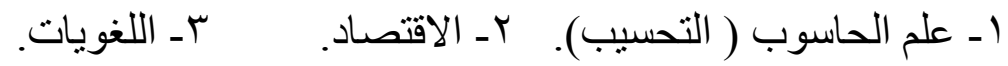

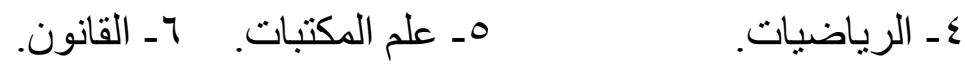

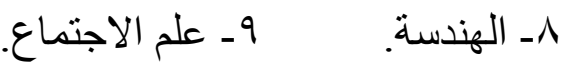

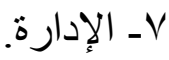

$$
\begin{aligned}
& \text { سار اسيفيك(09) Saracevic }
\end{aligned}
$$

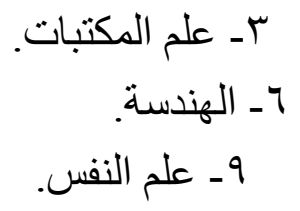

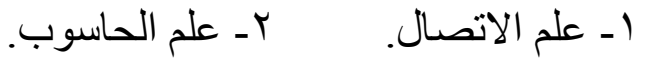

$$
\begin{aligned}
& \text { عـ الإدارة. }
\end{aligned}
$$

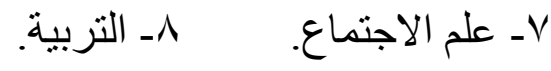

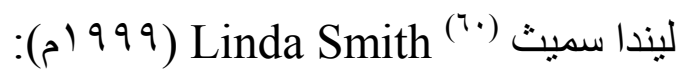

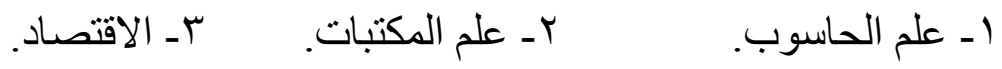

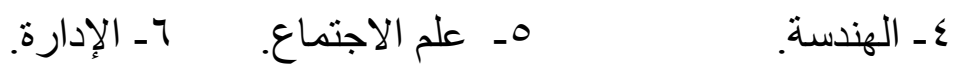

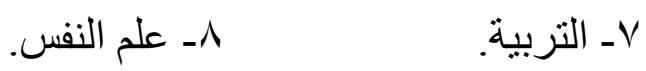

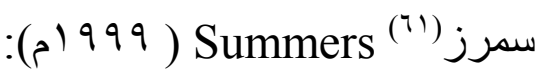

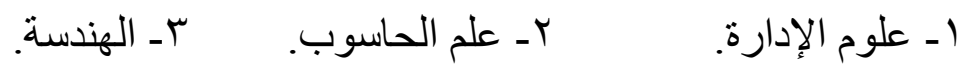

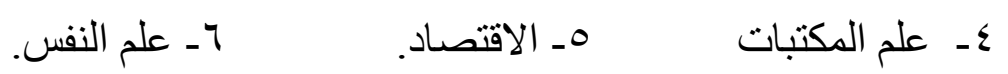

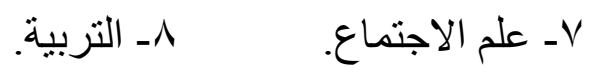

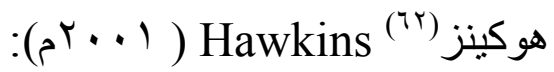

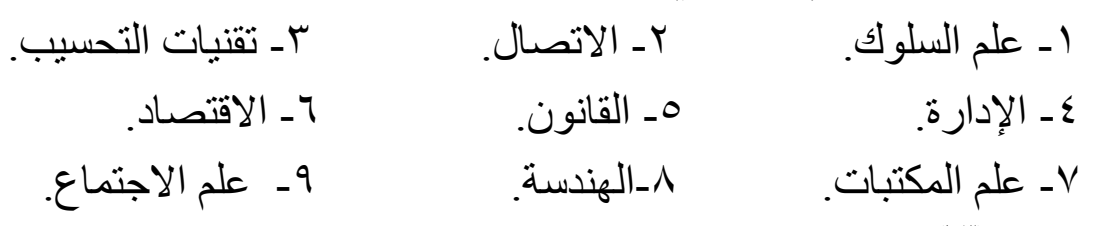

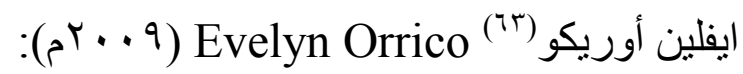

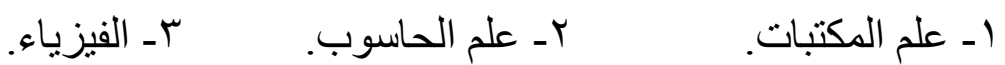

$$
\begin{aligned}
& \text { عـ الكيمياء. }
\end{aligned}
$$

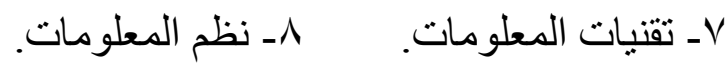

ومن خلال استعر اض هذه الدر اسات يمكن الخروج بعدد من المؤشر ات على النحو الآتي:

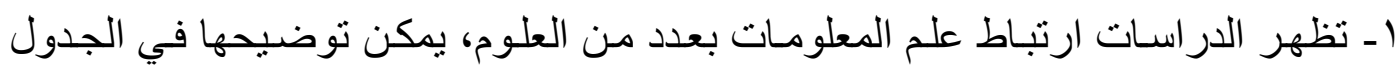


جدول ( ) الارتباطات الموضوعية لعلم المطلومات في الدراسات السابقة.

\begin{tabular}{|c|c|c|c|c|c|c|c|}
\hline المئوية & 5 & العلوم المرتبطة بعلم & r & المئوية & 5) & بعلم المعلومات المرتبطة & r \\
\hline$\% . r$ & 1 & الدر اسات البيليو مترية & rq & $\% 9 . r$ & rq & علم المكتبات & 1 \\
\hline$\% . r$ & 1 & علم المعاجم & $r$ & $\% \wedge . \Sigma$ & rq & علم النفس & r \\
\hline$\% .^{r}$ & 1 & علم المعرفة & TI & $\% \wedge$ & ro & الاقتصاد & $r$ \\
\hline$\% . r$ & 1 & علم الأعصاب & rr & $\% \vee . \vee$ & $r \varepsilon$ & الإدارة & $\varepsilon$ \\
\hline$\% . r$ & 1 & نظرية النظم العامة & rT & $\% \vee . \vee$ & $r \varepsilon$ & الهندسة & 0 \\
\hline$\% . r$ & 1 & البحوث الور اثية & Ts & $\% \vee . \vee$ & TE & والحاسوب & 7 \\
\hline$\% . r$ & 1 & البحث العلمي & ro & $\%\urcorner . \wedge$ & YI & علم الاجتماع & V \\
\hline$\% .^{r}$ & 1 & نظرية المعلومات & ry & $\%\urcorner . \wedge$ & YI & التربية & $\Lambda$ \\
\hline$\% .^{r}$ & 1 & إدارة الأعمال & rv & $\%\urcorner . \wedge$ & YI & الرياضيات & 9 \\
\hline$\% .^{r}$ & 1 & بحوث العمليات & rA & $\% \varepsilon$ & $1 T$ & اللغويات & 1 . \\
\hline$\% . r$ & 1 & علم التحكم & rq & \% & V & المنطق & 11 \\
\hline$\% .^{r}$ & 1 & علم النفس المعرفي & $\varepsilon$ & $\% \mu r$ & $\bar{V}$ & التقنيات & Ir \\
\hline$\% . r$ & 1 & علم وظائف الأعضاء & 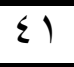 & $\%$ \% & $\varepsilon$ & الفلسفة & 14 \\
\hline$\% . r$ & 1 & علم الدماغ و المخ & $\sum r$ & $\%$ & $\varepsilon$ & الفنون & $1 \varepsilon$ \\
\hline$\% . r$ & 1 & الأكاء الاصطناعي & $\varepsilon r$ & $\% .9$ & $r$ & العلوم الطبيعية & 10 \\
\hline$\% .^{r}$ & 1 & الاتصال عن بعد & $\varepsilon \varepsilon$ & $\% .9$ & $r$ & العلوم التطبيقية & 17 \\
\hline$\% . r$ & 1 & معالجة البيانات & $\leqslant 0$ & $\% .9$ & $r$ & علوم الحياة & IV \\
\hline$\% .^{\Gamma}$ & 1 & الاتصالات الشخصية & $\leqslant 7$ & $\% .9$ & r & الإحصاء & 11 \\
\hline$\% . r$ & 1 & القر اءة & $\varepsilon V$ & $\% .7$ & $r$ & اللغات & 19 \\
\hline$\% .^{r}$ & 1 & التاريخ & $\Sigma \Lambda$ & $\% .7$ & $r$ & علم الدلالة & $r$. \\
\hline$\% . r$ & 1 & العلوم الطبية & $\varepsilon \wedge$ & $\% .7$ & $r$ & النشر و الطباعة & YI \\
\hline$\% .^{\Gamma}$ & 1 & التجارة & 0. & $\% .7$ & $r$ & بحوث العمليات & rY \\
\hline$\% .^{r}$ & 1 & نظرية المعرفة & 01 & $\% .7$ & r & العلوم السياسية & $r r$ \\
\hline$\% . r$ & 1 & علم البصريات & or & $\% .7$ & $r$ & الكيمياء & $r \varepsilon$ \\
\hline$\% .^{\Gamma}$ & 1 & العلم & or & $\% .7$ & $r$ & نظم المعلومات & To \\
\hline$\% . r$ & 1 & الطاقة & $0 \leqslant$ & $\% .7$ & $r$ & الهندسة الإلكترونية & YT \\
\hline$\% . r$ & 1 & علم العلامات & 00 & $\% .7$ & r & علم السلوك & TV \\
\hline$\% . r$ & 1 & الثقافة & 07 & $\% .7$ & $r$ & الفيزياء & $r \wedge$ \\
\hline$\% 1 \cdots$ & & النسبة المئوية & \multicolumn{2}{|c|}{ W } & \multicolumn{3}{|c|}{ إجمالي التكر ارات } \\
\hline
\end{tabular}


ومن خلال فحص الجدول السابق، يمكن القول إن ارتباطات الموضو عات لعلم المعلومـات ـ

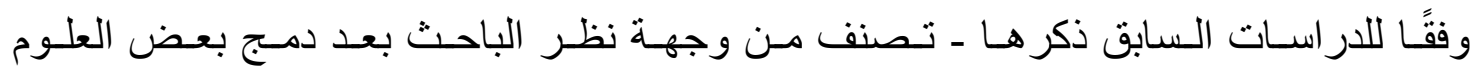

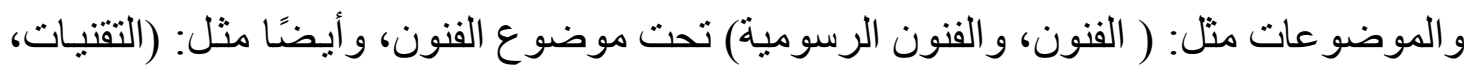
و الإلكترونيات، وتقنيات التحسيب) تحت موضوع التقنيات في ثناث فئات رئيسة كما يأني: أـ ارتباطات أوليـة Primary: وهى وتفي المجالات الموضو عية التى ترتبط موضو عيًا

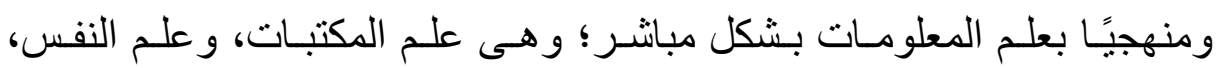

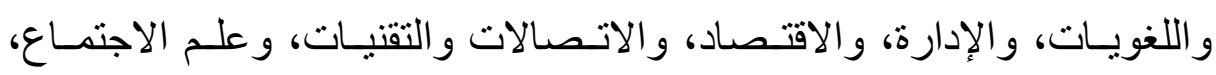

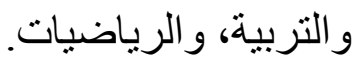

بـ ارتباطات الدرجة الثانية Secondary: و هى المجالات الموضو عية التى ترتبط

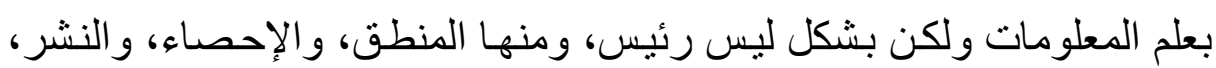
و اللغات، و الفنون، و الفلسفة. تـ ارتباطـات هامشية Marginal: وهى المجـالات الموضـوعية التى ترتبط بعلم

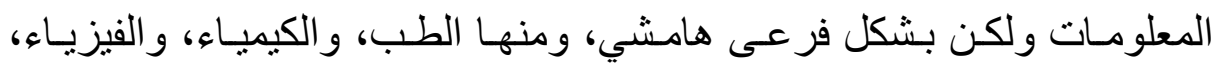

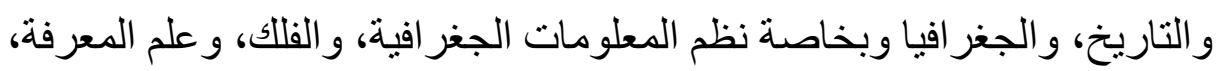
و علم السلوك، و البحث العلمي، ونظم المعلومات و المعرفة .

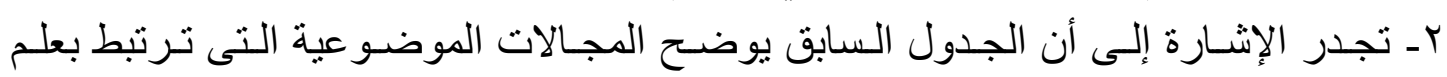
المعلو مات، وليست المجالات و التخصصات الموضو عية التى تهنم بدر اسة المعلومات؛ لأنه من وجهة نظر الباحث فإن المعلومات هى محور ولُب المعرفة البشرية بشكل عام.

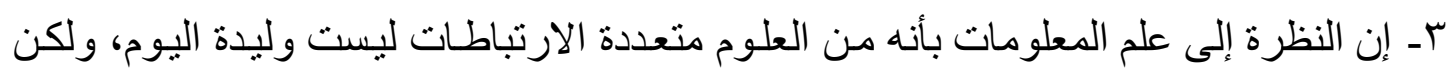
نشأت مع بدايات علم المعلومات نفسه في ستينيات القرن العشرين.

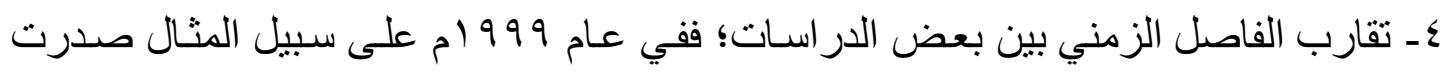

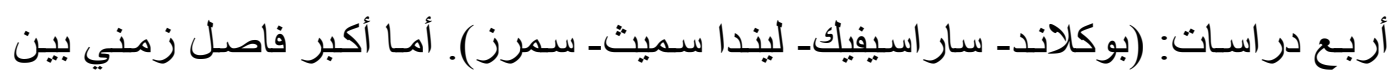

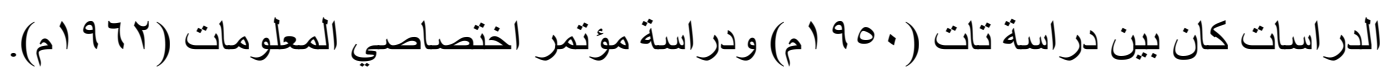

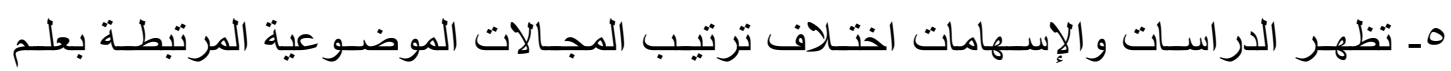

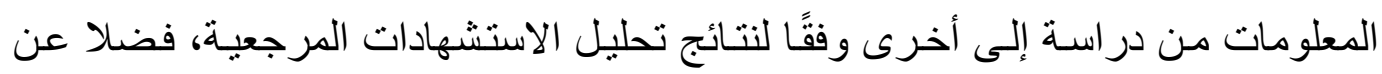

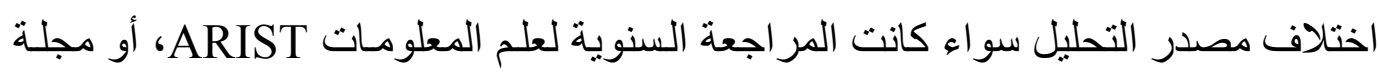

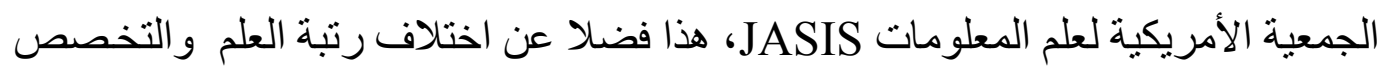

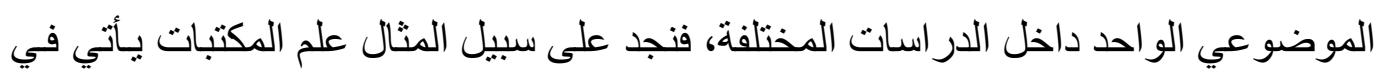

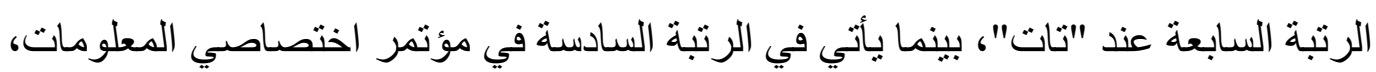




\section{ب / الإطار الفكري لعلم المعلومات:}

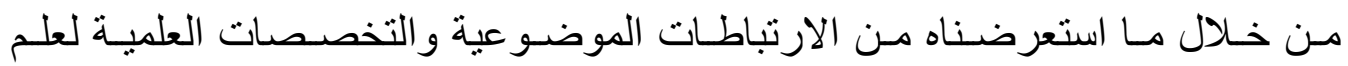
المعلومات، فإن الباحث يقدم هذا الرسم التخطيطي؛ و الذى يوضح الإطسار الفكري أو خريطة المفاهيم Concepts Map لعلم المعلومات من وجهة نظر الباحث على النحو الآتي:

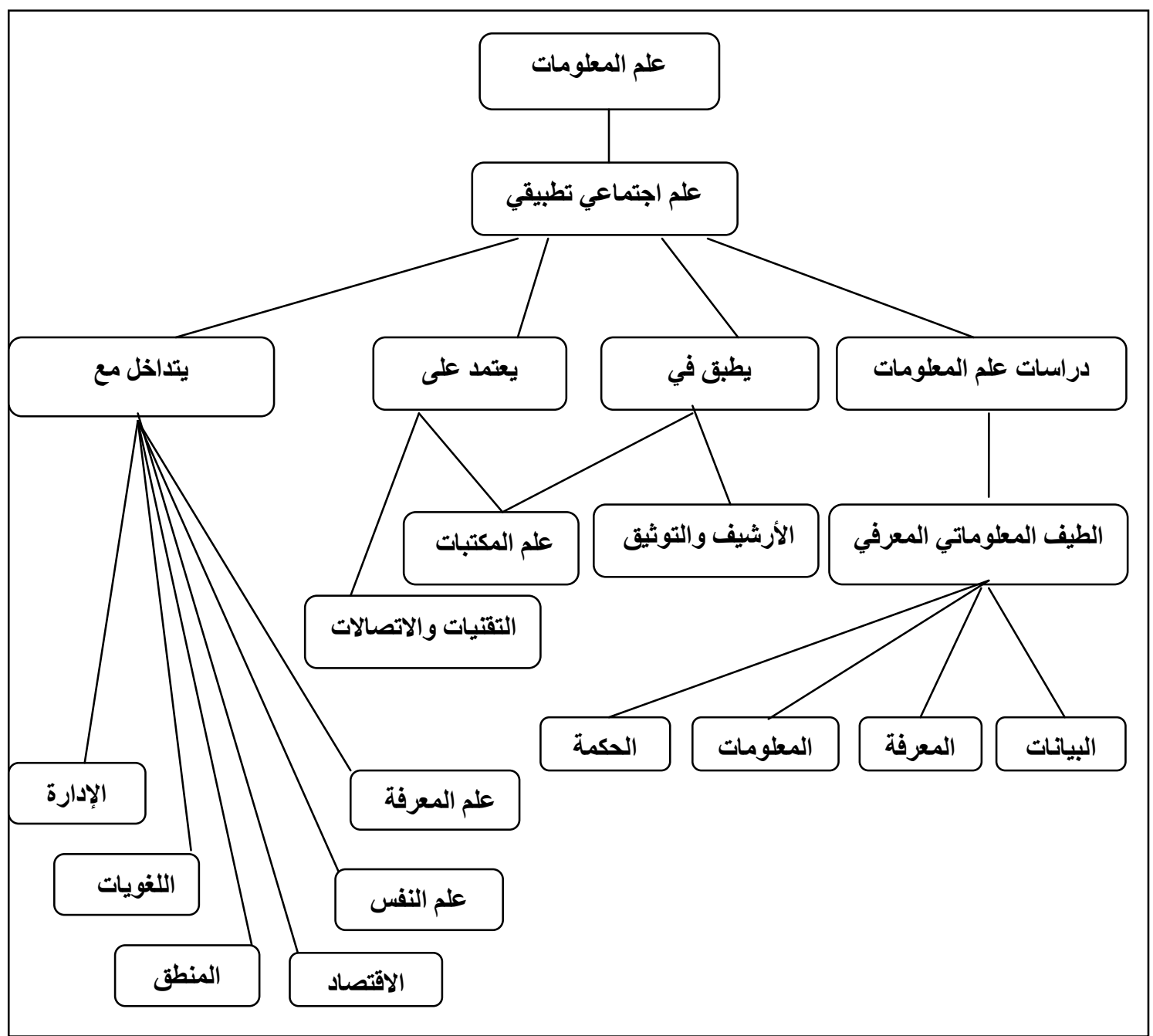

شكل رقم ( r ) الإطار الفكري لعلم المعلومات.

وبالنظر إلى الثكل السابق ، فإنه يمكن الخروج بالملاحظات الآتية: 1 ـ انتماء علم المعلومات إلى خريطة العلوم الاجتماعية، مع الاعتر اف بتداخله وارتباطه أيضًا

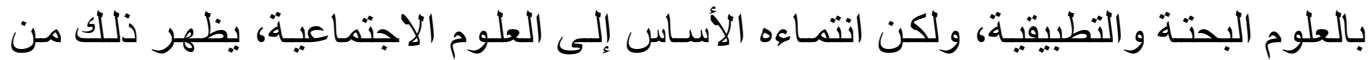
خلال استعر اض شجرة مؤلفي علم المعلومات. 


\section{r- يوضح التصور السابق أربعة محاور رئيسة كما يأتي:}

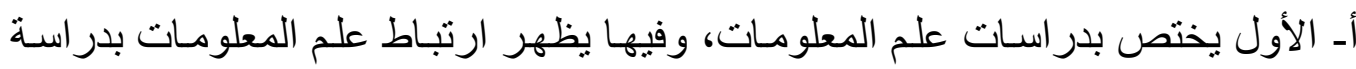

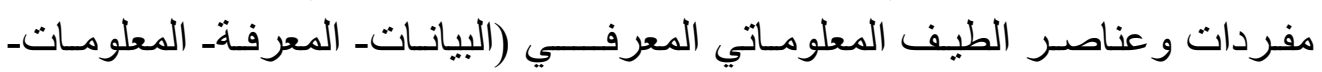

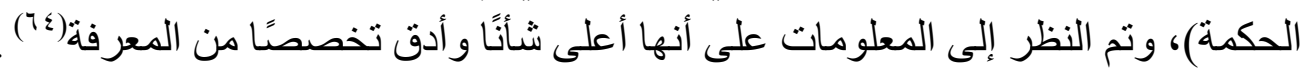

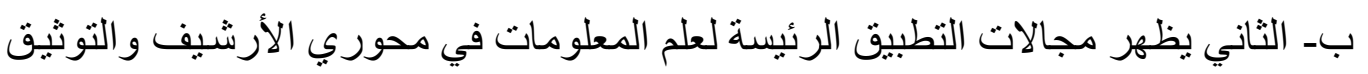

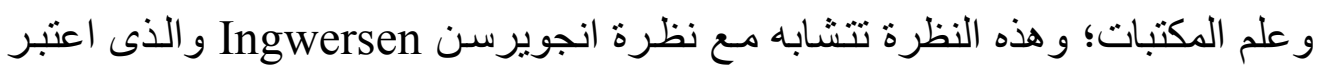
فيها أن علم المعلومات يطبق في التوثيق و علم المكتبات بشكل أكثر من غيرة هما.

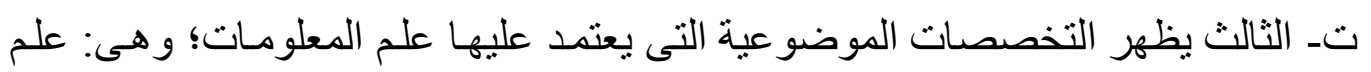

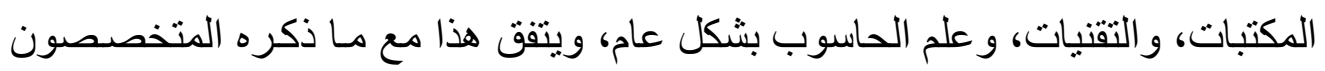
من قبل بأن من خصائص علم المعلومات ما يعرف وبات علمت الحتمية التقنية.

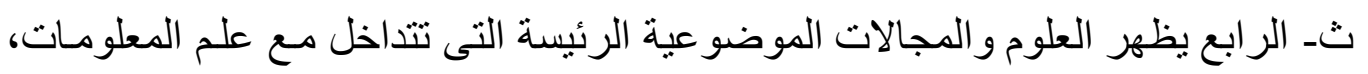

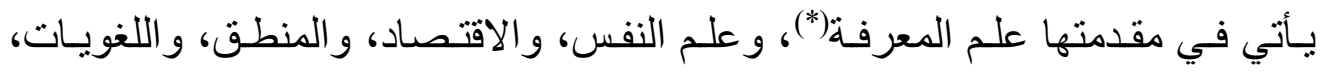
و الإدارة.

ب- يظهر الشكل السابق الارتباط والتداخل بين علم المكتبات و علم المعلومات فمجال المكتبـات مجال ارتباط وبناء وتطبيق بعلم المعلومات، ويمكن القول إنه قاعدة علم المعلومات المهنية.

\section{ثالثًا: الخريطة المعرفية والبنية الاخلية لعلم المعلومات:}

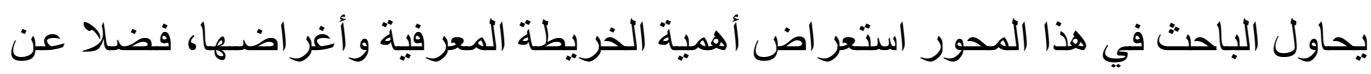

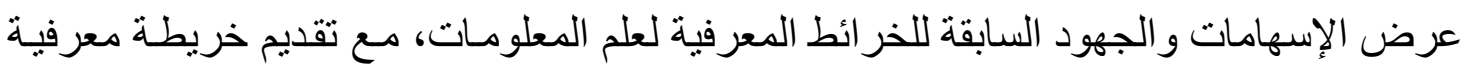
مقترحة لعلم المعلومات من وجهة نظر الباحثاث.

\section{ب/ ا أهمية الخريطة المعرفية لعلم المعلومات:}

ا ـ يمكن أن تلعب الخريطة المعرفية لعلم المعلومـات دورًا مهمًا كمنصة (كمرجعيـة)

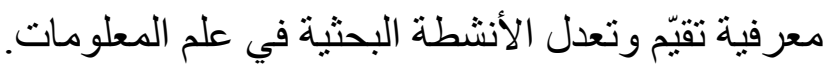

Y ـ تسهم في تطوير مناهج در اسات علم المعلومات(10).

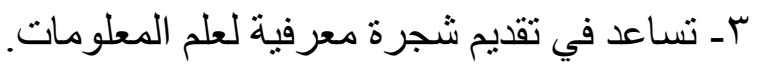

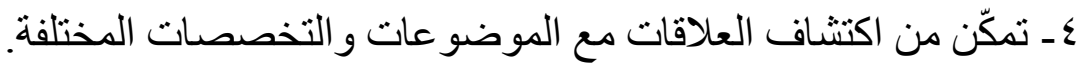

هـ إقامة جسر Crossover من خلال البحث داخل الارتباطات المختلفة(17).

7ـ إلقاء الضوء على جـ إنتاج وبث المعلومات.

V - إيجاد خر ائط الثبكات العلمية و الإنسانية.

(*) علم المعرفة من العلوم متعدة الارتباطات والتي تتداخل مع علم المعلومات وخاصة في مجالي الذكاء الاصطناعي والتفاعل بين

الإنسان والحاسوب وليس بديلا عنه (الباحث). 
r/ r أغراض استخدام خريطة المعرفة: ويمكن أن تستخدم الخريطة المعرفية باعتبار ها:

ا ـ أداة شخصية لبناء معرفة اجتماعية.

r - وسيلة لبناء شخصية علمية.

بـ أداة شخصية لبناء معرفة اجتماعية.

ع - وسيلة لبناء شخصية علمية.

هـ ميدانًا معر فيًا للآر اءه و الأفكار.

7- منهجا لتوليد الأفكار.

V- أرضية بنـاء المكانز و الأنطولوجيات وخطط التصنيف في مجـال علم المكتبـات

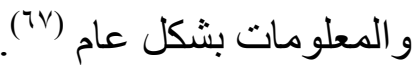

Aـ تسلط الضوء على محاور علم المعلومات.

r/ ا الإسهامات في وضع خرائط معرفية داخلية لعلم المعلومات:

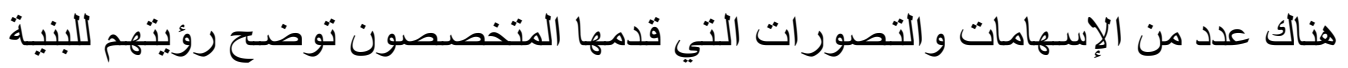
الداخلية لعلم المعلومات، يمكن إلقاء الضوء على على بعضها لإنها على النحو الآتي:

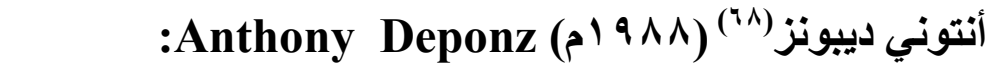

$$
\text { צ זـ ـ التزويد. }
$$$$
\text { 1 الحدث. }
$$

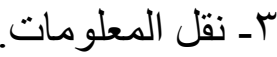

0ـ المر افق.

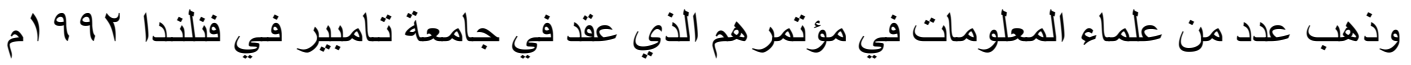

إلى أن المجالات التالية تقع في قلب علم المعلومات؛ وهيى على النحو الآتي (79):

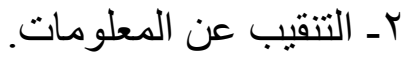

ا ـ الانفورماتريكا .

ع - إدارة المعلومات.

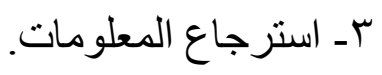

0ـ تصميم نظم استرجاع المعلومات.

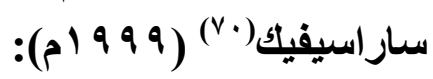

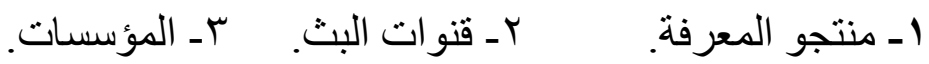

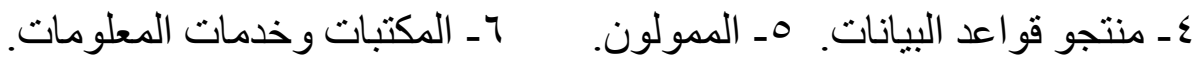

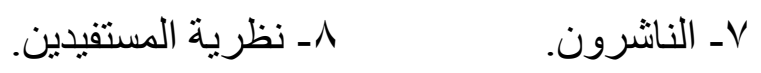

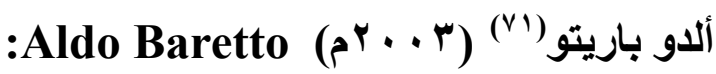

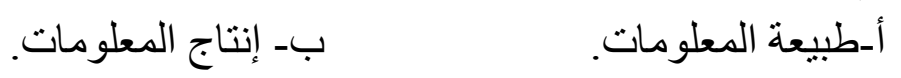

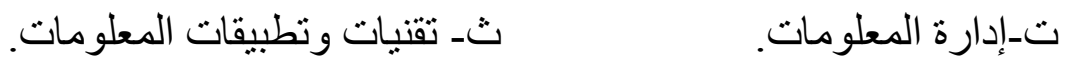




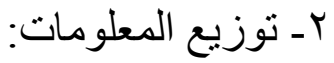

$$
\begin{aligned}
& \text { أـ تجمعات المعلومات و المستقيدين. بـ اتصال المعلومات. }
\end{aligned}
$$

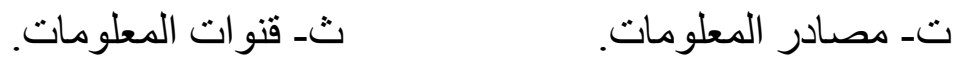

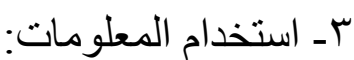

$$
\begin{aligned}
& \text { بـ استخدام المعلومات وتطبيقاتها. } \\
& \text { أـ الوصول إلى المعلومات. } \\
& \text { ثـ تمثيل المعلومات. } \\
& \text { تـ معرفة مفاهيم المعلومات. توصول. } \\
& \text { ج-إنتاج المعرفة. } \\
& \text { ع ـ تاريخ وفلسفة و أخلاقيات المعلو مات: }
\end{aligned}
$$

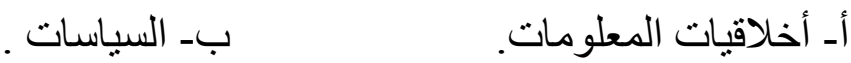

$$
\begin{aligned}
& \text { ثـ_التاريخـ الفلسفةـ البيئة. } \\
& \text { تـ السمات العالمية. }
\end{aligned}
$$

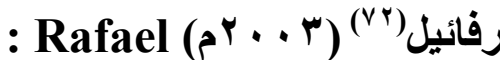

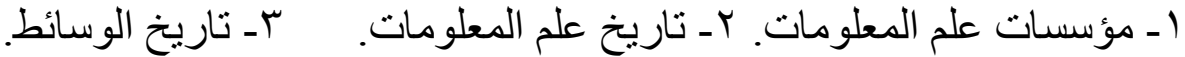

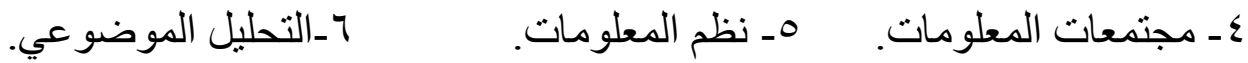

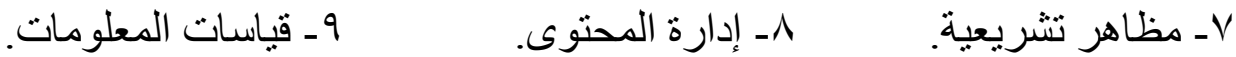

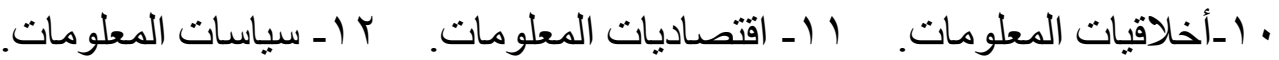

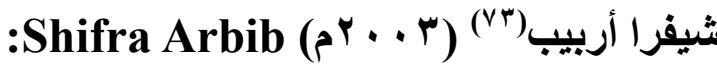

$$
\begin{aligned}
& \text { أـ أساسيات المعلومات. المنهجية. }
\end{aligned}
$$

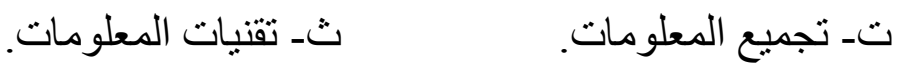

$$
\begin{aligned}
& \text { جـ تتظيم و استرجاع المعلومات. ــــــاعة المعلومات و إدار اتها. } \\
& \text { خــ أخلاقيات وقو انين المعلومات. دـ در اسات المستفيدين. }
\end{aligned}
$$

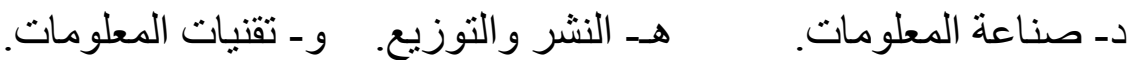

$$
\begin{aligned}
& \text { زـ نظم المعلومات الرقمية. ـــ المصادر الموضو عية والتطبيقات. }
\end{aligned}
$$

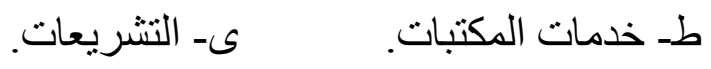

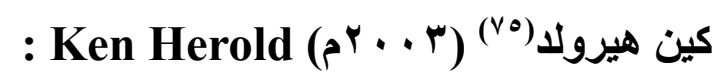

$$
\text { زـ أـ المفاهيخ. }
$$

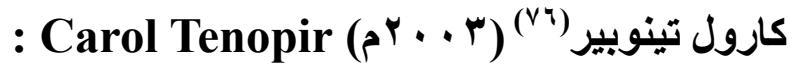




$$
\begin{aligned}
& \text { أـ تنظيم المعلومات و المعرفة. بـ استرجاع و استخدام المعلومات و المعرفة. }
\end{aligned}
$$

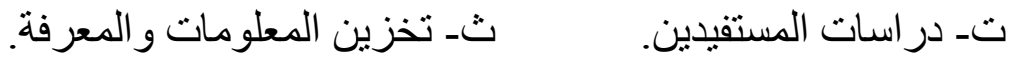

$$
\begin{aligned}
& \text { ج- تاريخ وفلسفة علم المعلومات. حــ تنظيم و إدارة المعلومات. } \\
& \text { : Clare Beghtol (كلير بيجتول }
\end{aligned}
$$

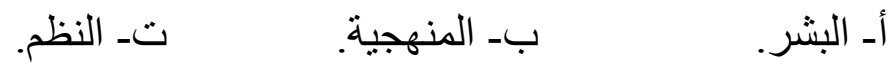

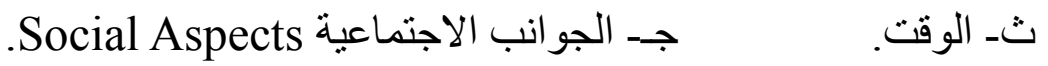

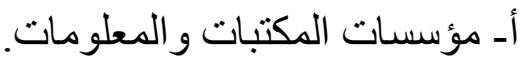

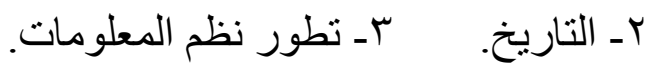

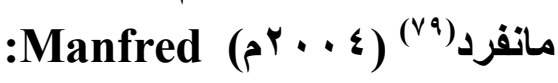

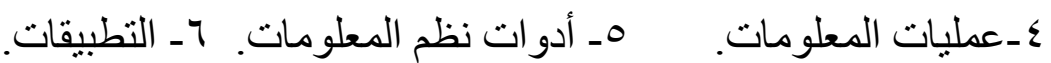

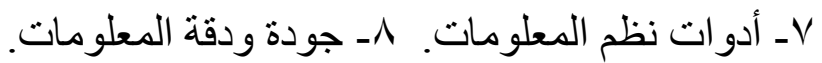

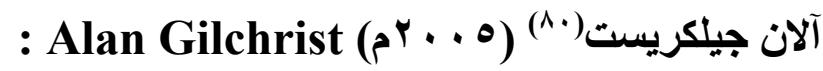

$$
\begin{aligned}
& \text { أـ أساسيات علم المعلومات. }
\end{aligned}
$$

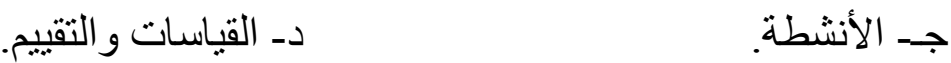

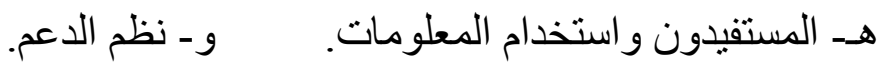

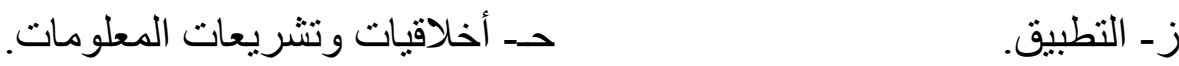

$$
\begin{aligned}
& \text { زينس(^) Z Zins }
\end{aligned}
$$

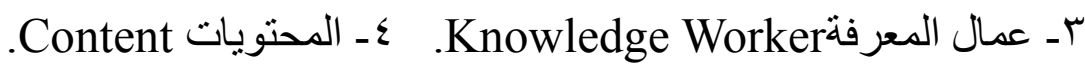

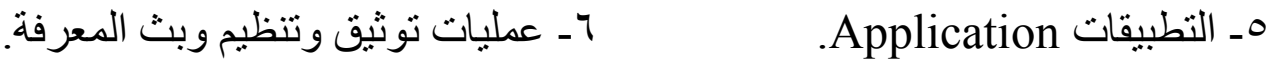

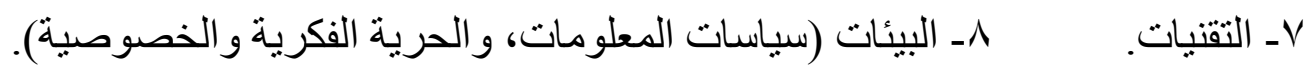

$$
9 \text { ـ منظمات المعرفة. }
$$

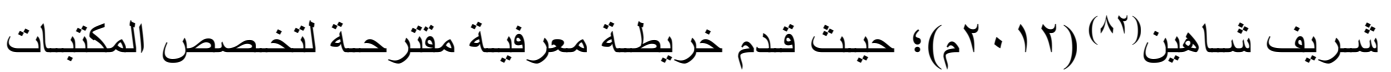

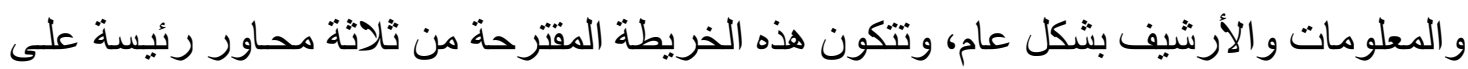

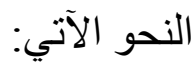

المحور الأول: بتكون من 7 قطاعات رئيسة:

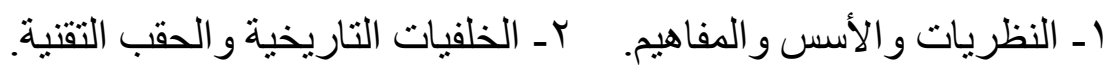

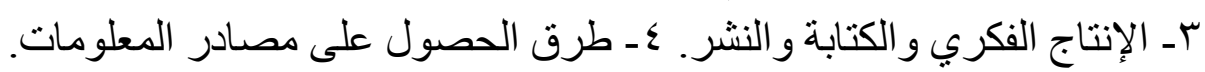




$$
\begin{aligned}
& \text { 0ـ تتظيم مصادر المعلومات. خدمات المعلومات. } \\
& \text { المحور الثاني: يتكون من r تسهيلات / ميسر ات رئيسة: }
\end{aligned}
$$

ا ـ البشر (مؤلفون-مترجمون...). ب بـ المؤسسات (المكتبات ومر اكز المعلومات).

rـ النظم (قو اعد البيانات و المعرفةـ نظم الأرشفة الإلكترونية).

المحور الثالث: يتكون من V وجوه/ أقسام فرعية:

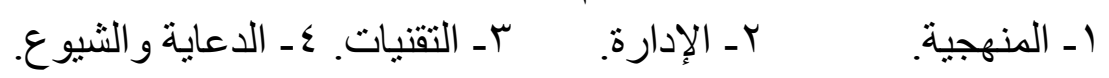

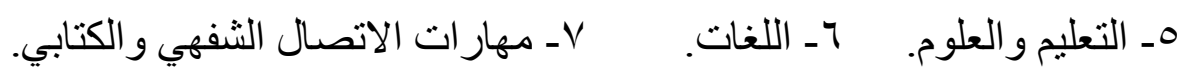

ومن خلال استعر اض بعض الجهود و الإسهامات في وضع خربطة معرفية لعلم المعلومات

يمكن الخروج بالملاحظات الآتية:

ا ـ هذه الإسهامات تعكس الرؤية العلمية لصاحب الماتبة الإسهام.

Y - هذه الإسهامات توضح الطبيعة المتداخلة لعلم المعلومات.

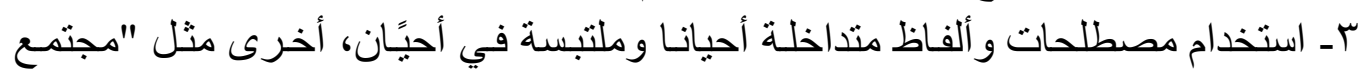

المستفيدين- نظرية المستفيدين- در اسات المستفيدين".

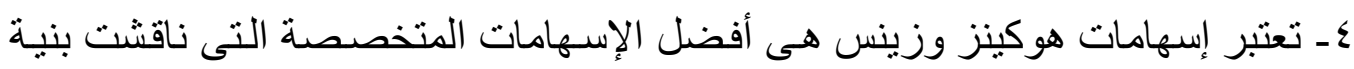

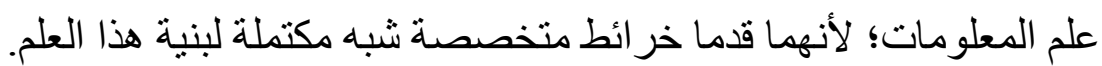

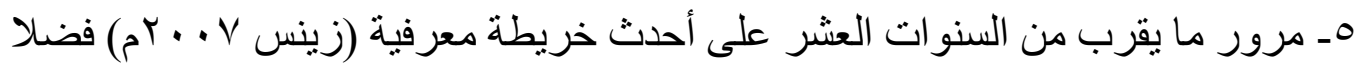

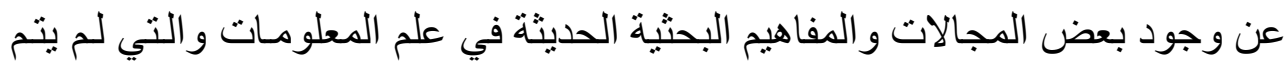

دمجها في الخر ائط السابقة؛ وهو ما دفع الباحث إلى تقديم خريطة معرفية مقترحة.

r/ ع الخريطة المعرفية المقترحة لعلم المعلومات ومنهجية إعدادها:

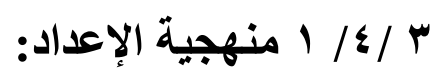

يقدم الباحث هنا رؤيته لخريطة معرفية لعلم المعلومات، هذه الخربطة تمثنل وجهة نظر

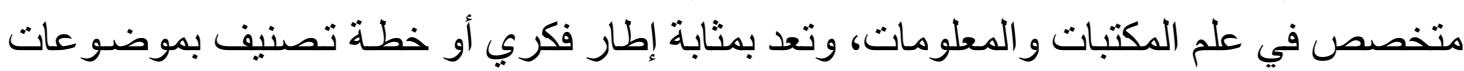

ومفاهيم علم المعلومات، وقد اعتمد الباحث في منهجية إعدادها على العناصر الآتية:

ا ـ مر اجعة الإنتاج الفكري المتخصص في في علم المعلومات المدات العربي والأجنبي.

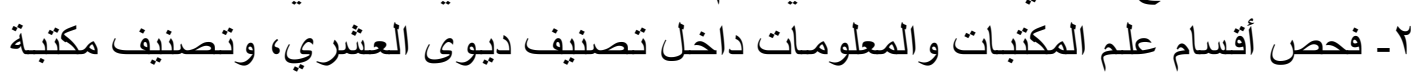

$$
\text { الكونجرس. }
$$

بـ الاطلاع على أقسام علم المكتبـات و المعلومات في أدلة الويب Web Directories دثل دمان دليل BUBL م ، ودليل Infomine.

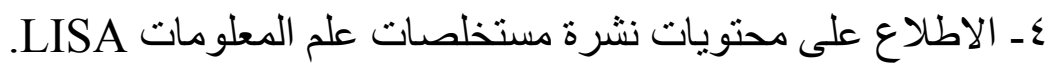

ــ الاطلاع على بر امج المؤتمرات و الندو ات العربية و الأجنبية.

جـ فحص عنـاوين بعض الـدوريات المتخصـصة في علـم المعلومـات، وعلـم المكتبـات 
Vـ البحث في المعاجم و المكانز المتخصصة في علم المعلومات.

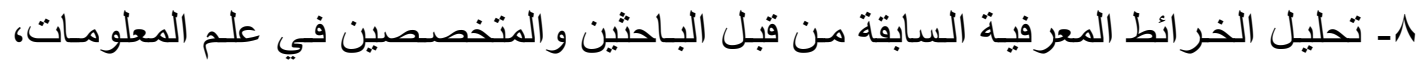
وبخاصة الخر ائط المعرفية المقدمة من قبل زينس Zins، و هوكينز Hawkins.

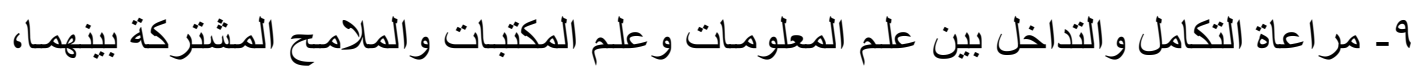
و ومنها در اسات المستفيدين. ـ ـ ـ مر اعاة خصائص علم المعلومات في الخربطة المعرفية المقترحة، ومنها الطبيعة متعددة

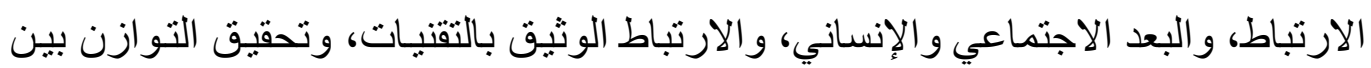

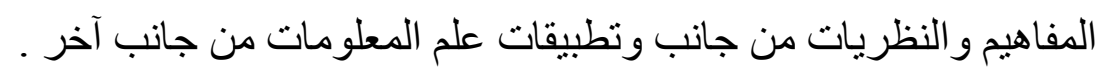
1 ا ـ ويؤكد الباحث على أن هذه الخريطة المقترحة قابلة للتعديل سواء بالحذف أو الإضـافة أو هئ الامج بين محاور ها. r ا ـ تتكون الخريطة المعرفية المقترحة من عشرة محاور رئيسة كما في الثكل التالي:

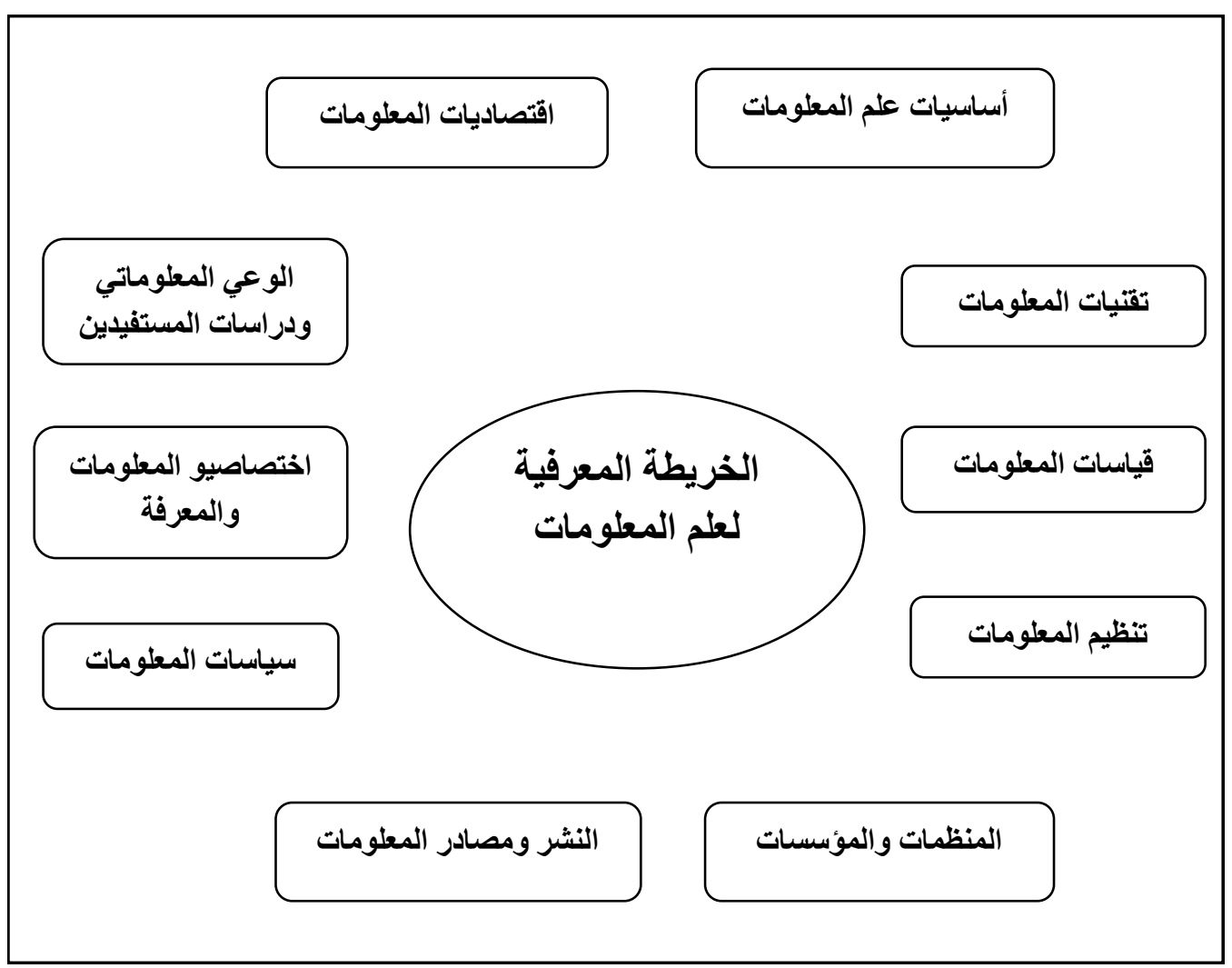

شكل رقم (") رسم تخطيطي يوضح مكونات الخريطة المعرفية المقترحة. 
ب/ ؟ / آ هيكل الخريطة المعرفية المقترحة.

\begin{tabular}{|c|c|}
\hline مكونـات المحور & ور الرئيس \\
\hline 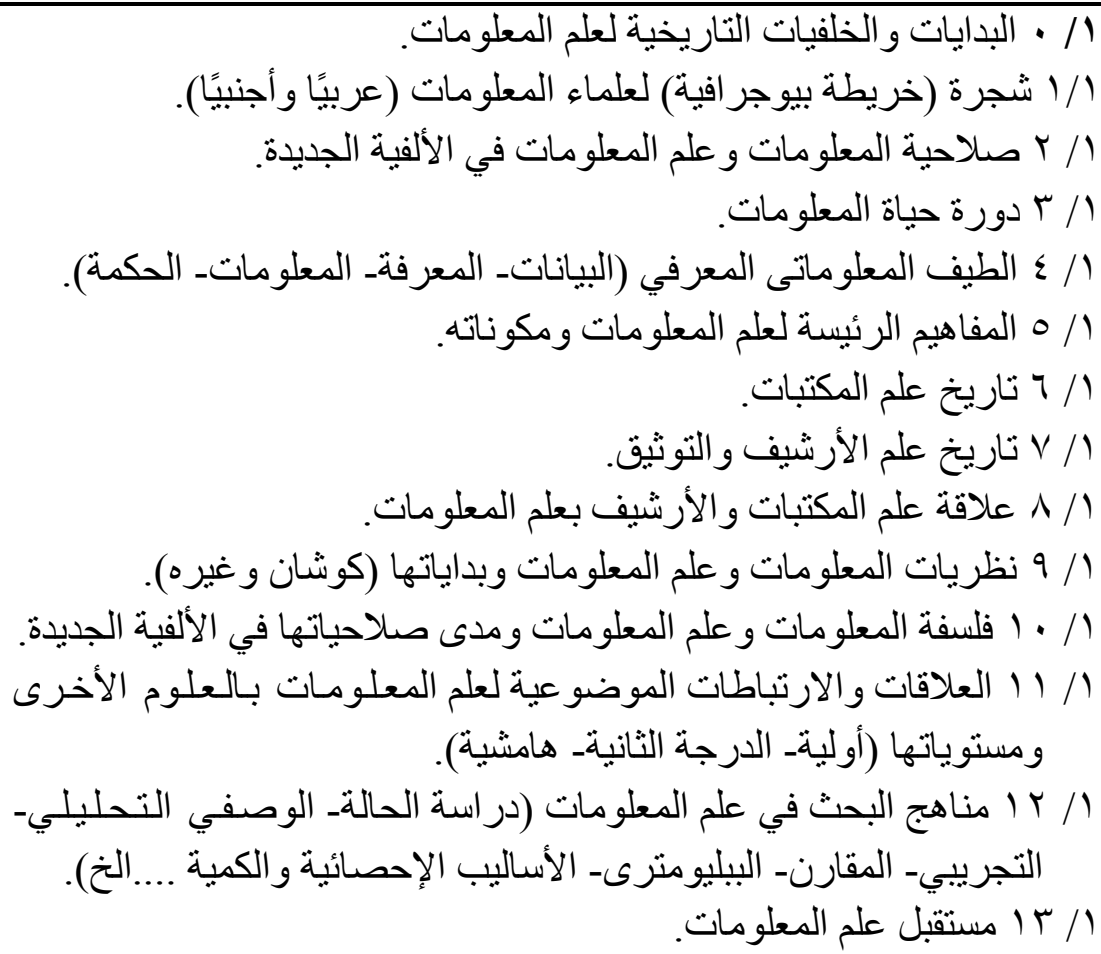 & أسطاسيات علم المعات \\
\hline 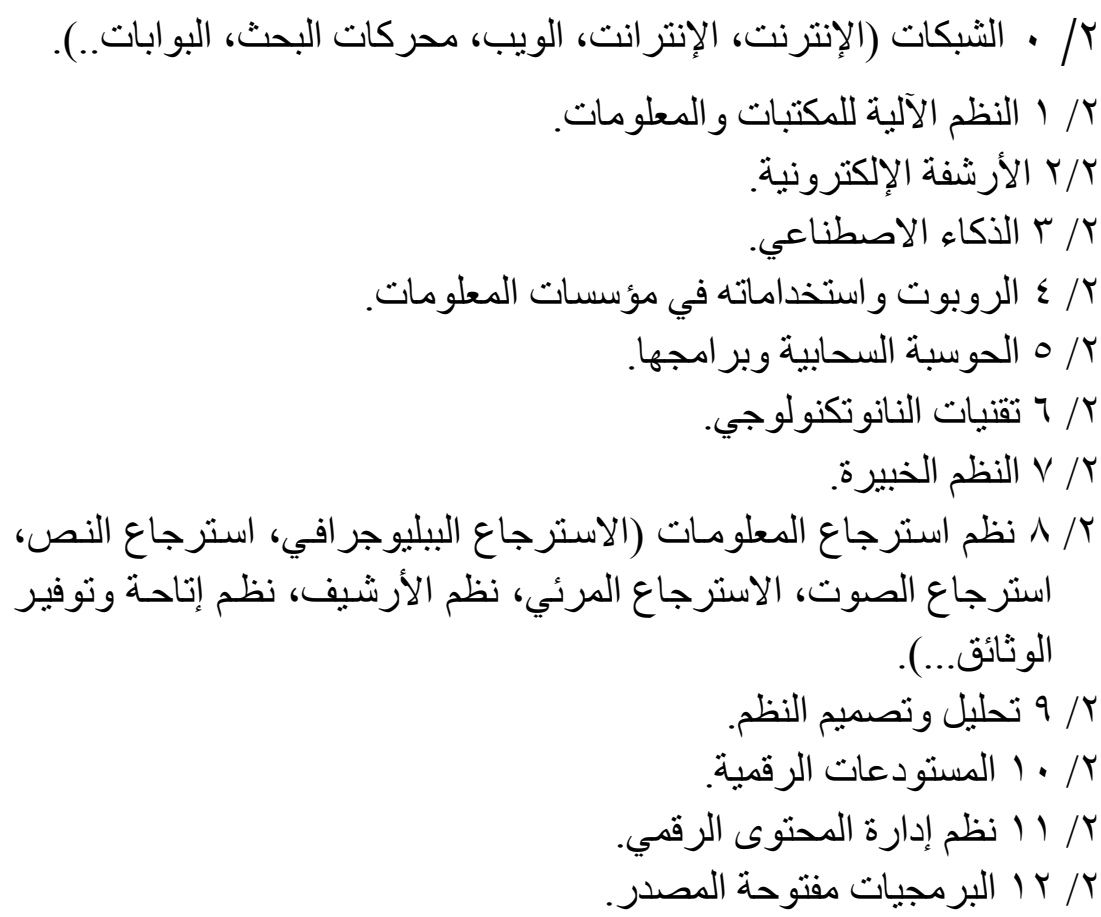 & تقتيات المعلومات \\
\hline
\end{tabular}




\begin{tabular}{|c|c|}
\hline 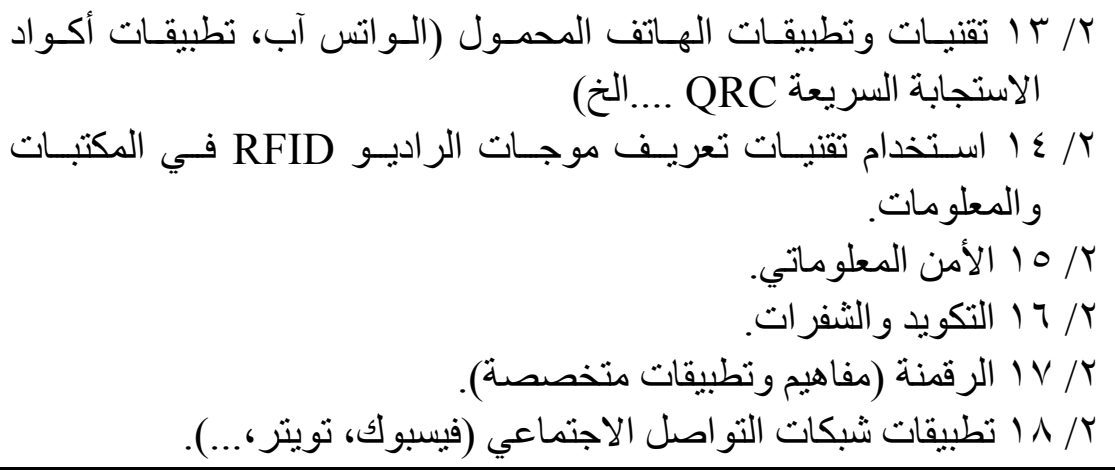 & \\
\hline 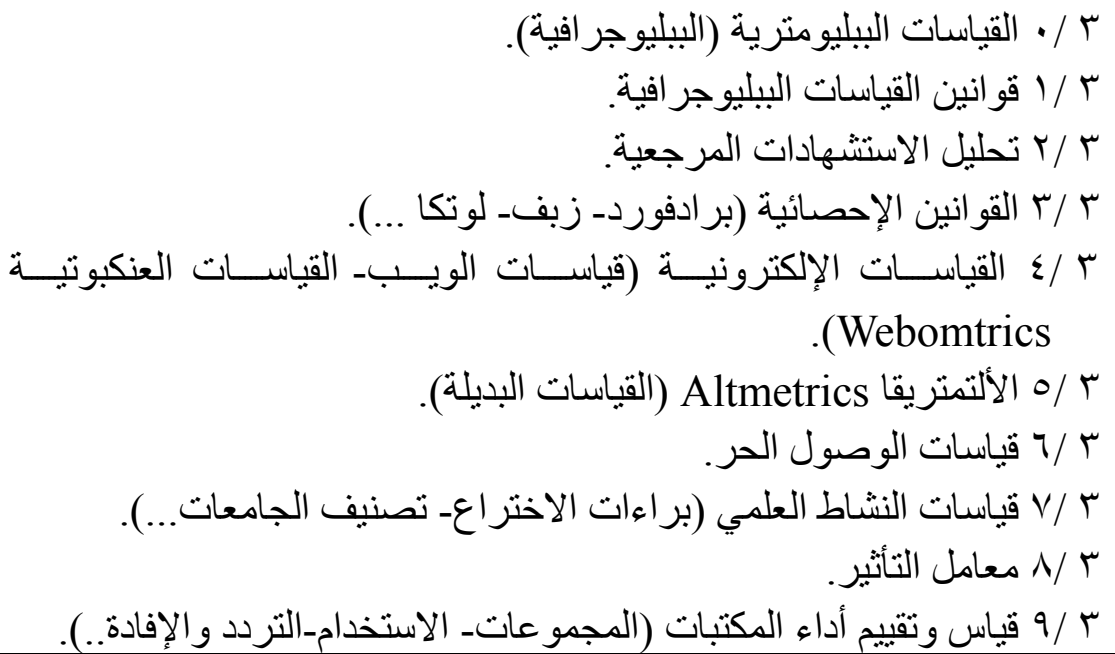 & قياسـات المعلومات \\
\hline 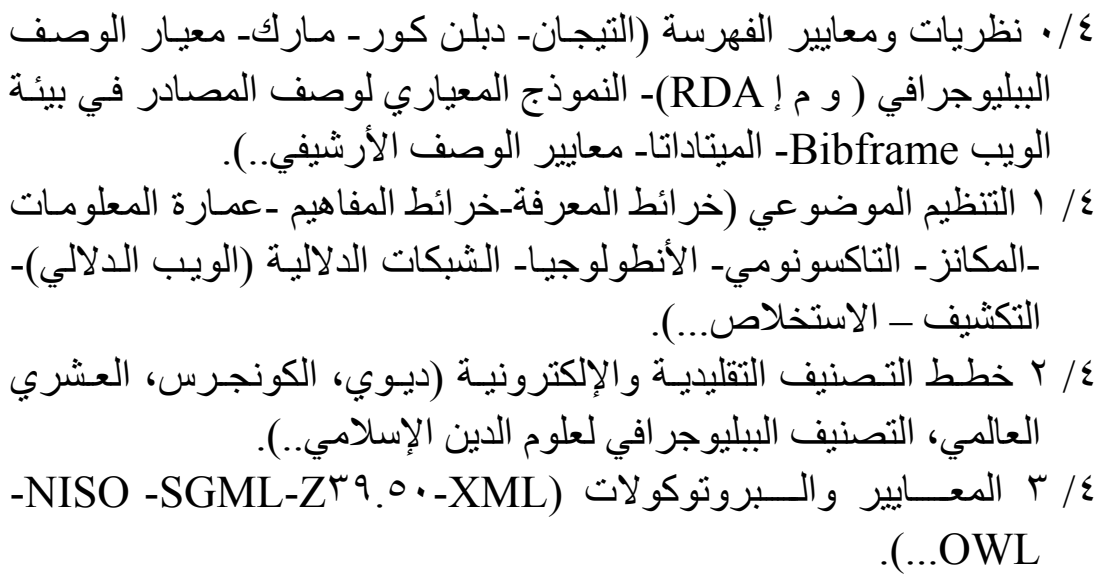 & تنظيم المعلومات \\
\hline 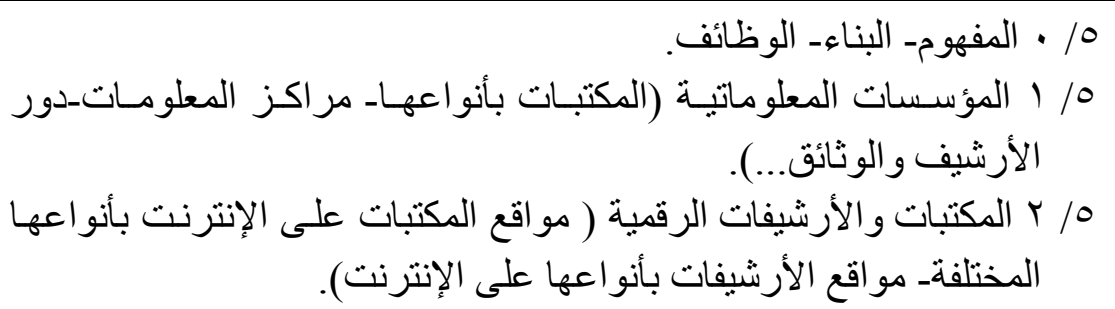 & المحور الخامس \\
\hline
\end{tabular}




\begin{tabular}{|c|c|}
\hline 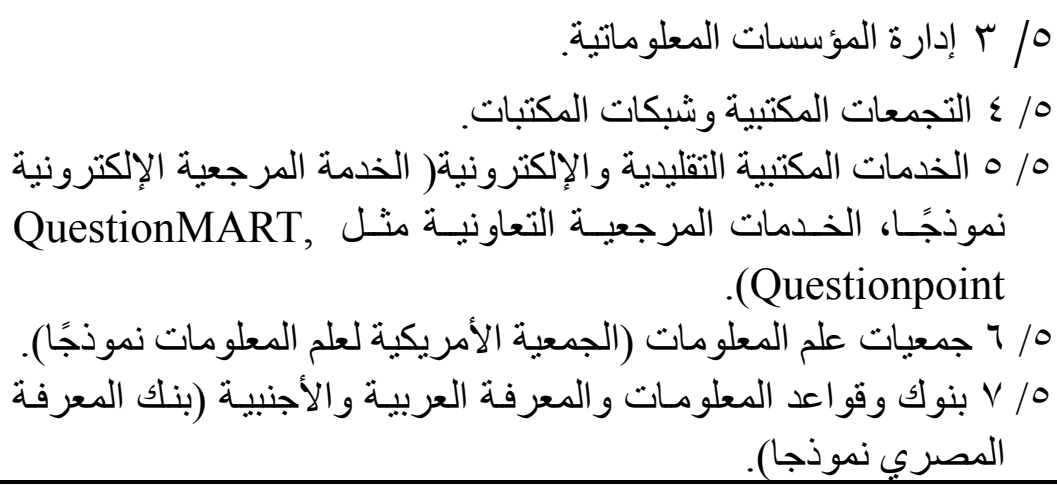 & \\
\hline 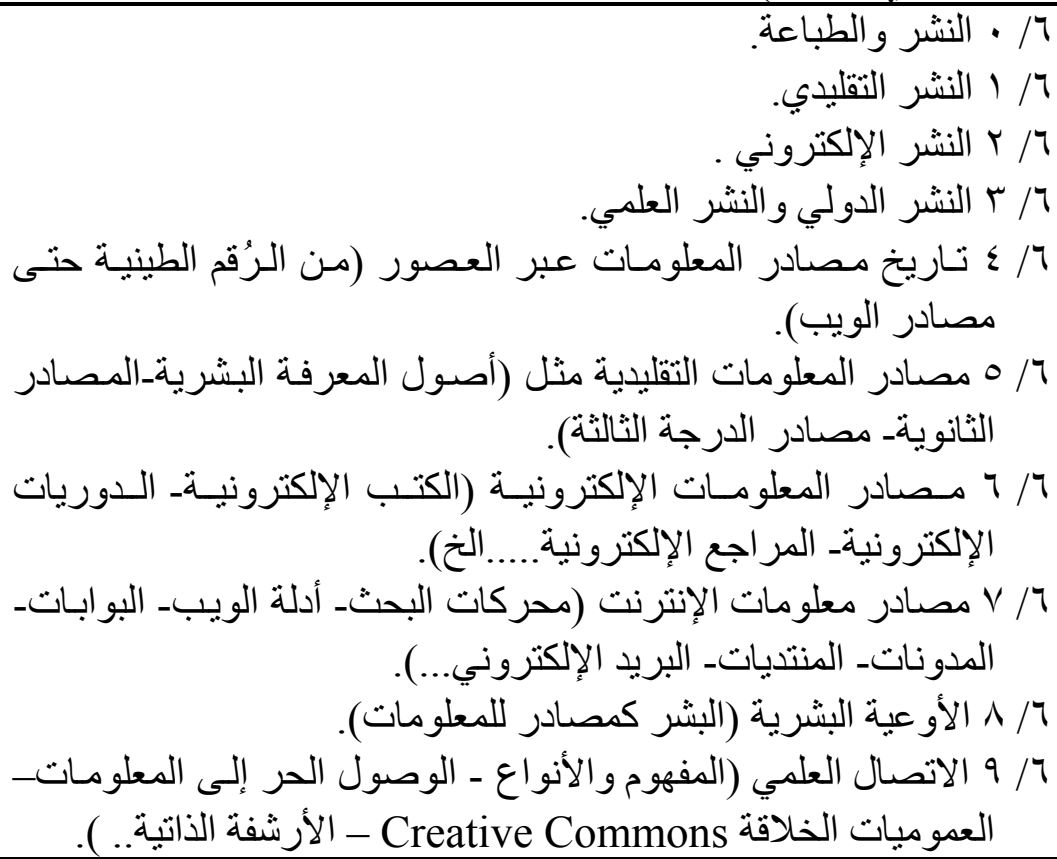 & المحور السادس \\
\hline 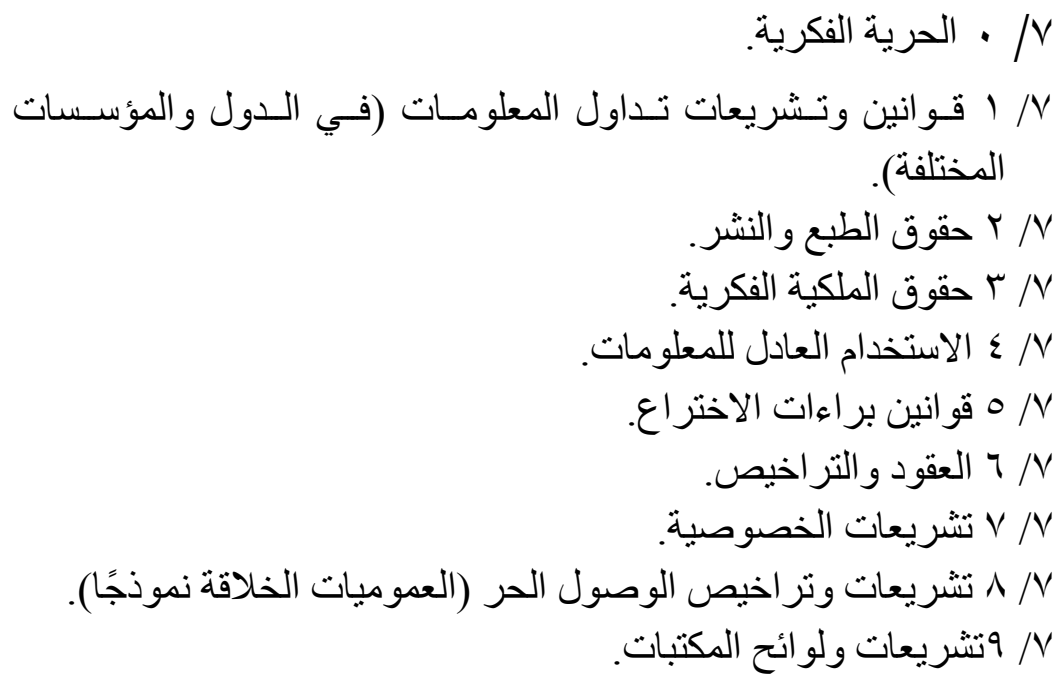 & سياسات المعلور السابع \\
\hline
\end{tabular}




\begin{tabular}{|c|c|}
\hline 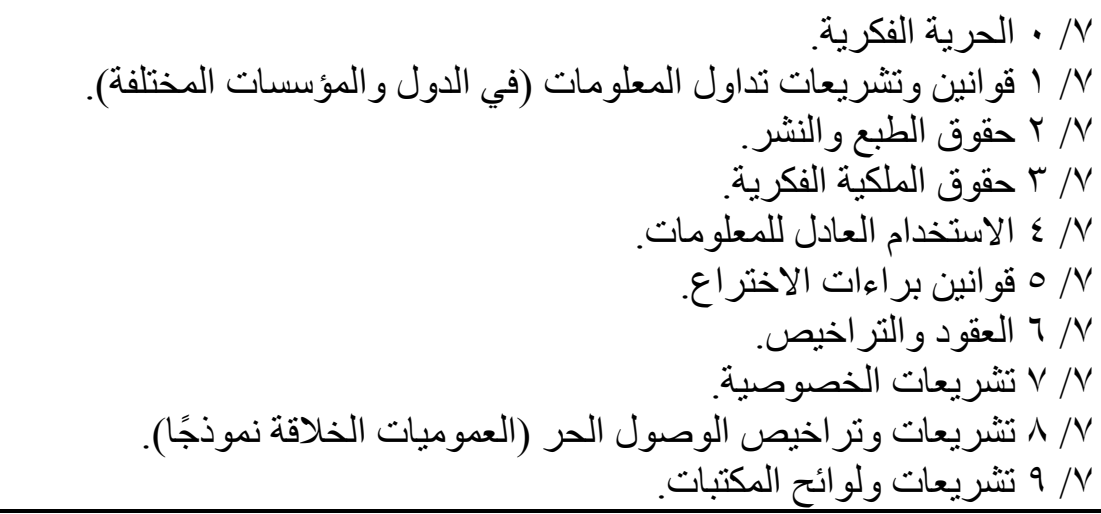 & سياسات المعلومات المابع \\
\hline 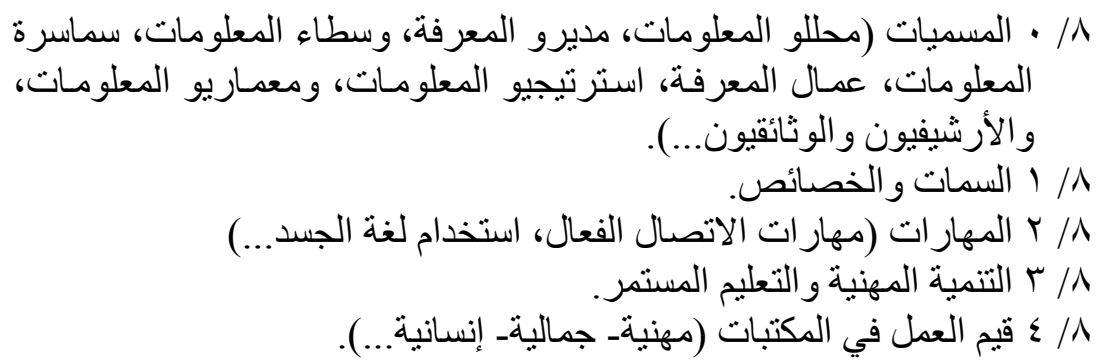 & اختصاصيو المعلومات \\
\hline 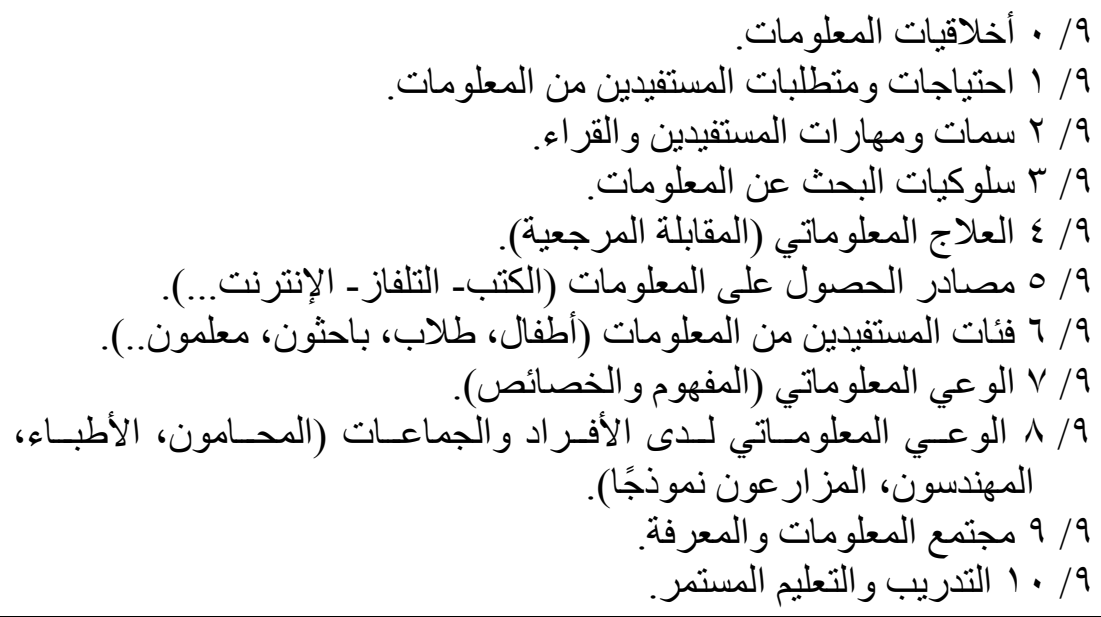 & والوعي المعلوماتيّين المستفيدين \\
\hline 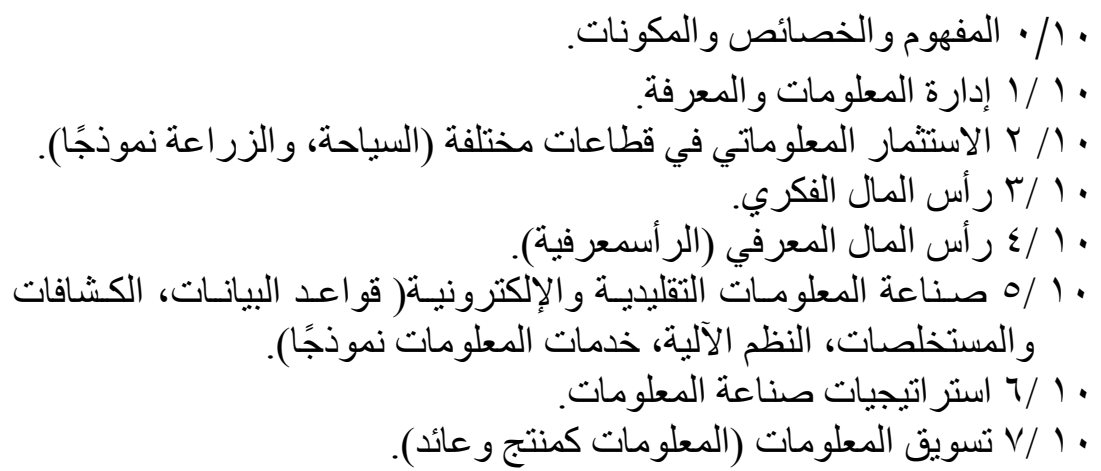 & اقتصاديات المعلومات العاشر \\
\hline
\end{tabular}


توصلت الدر اسة إلى مجمو عة من النتائج، ومنها:

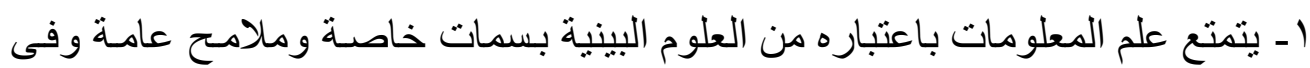
مقدمتها أنه علم متعدد الارتباطات بعدد من العلوم الأخرى، و الارثباط بالتقنيات،

$$
\text { فضلا عن الارتباط بالجانب الإنساني و الاجتماعي. }
$$

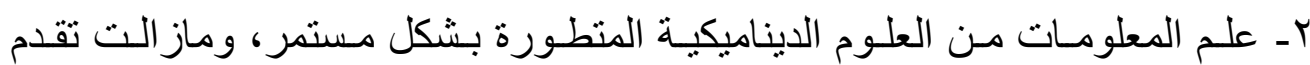

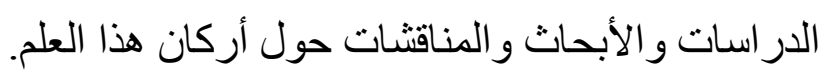

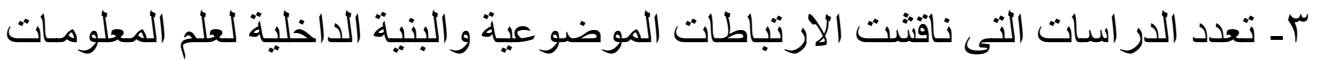
منذ نشأة هذا العلم في ستينيات القرن العشرين وحتى السنوات الأولى من الألفيـة

\section{الثالثة.}

ع - يؤكد الباحث على صلاحية استخدام المعلومات و علم المعلومات في الألفية الجديدة.

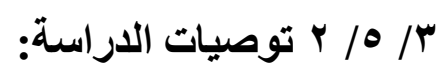

$$
\text { يوصي الباحث بعدد من التوصيات، منها ما بأني: }
$$

ا ـ إجر اء مزيد من الدر اسـات التى تتتـاول خر ائط المعرفـة في مجـال المكتبـات و علم

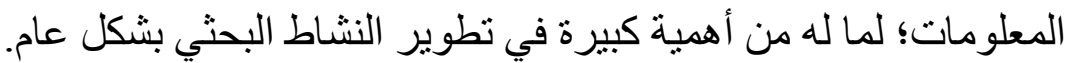

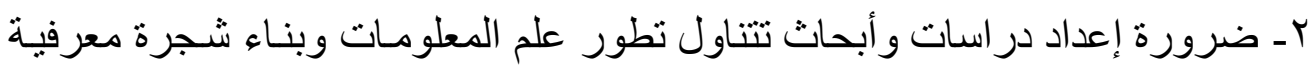
لهذا العلم، على أن يتم ذلك كل عشر سنوات على الأقل للكشف عما بستجد إزاء

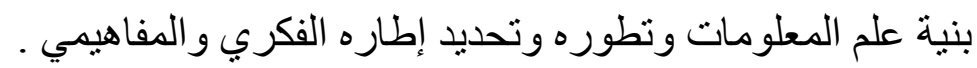

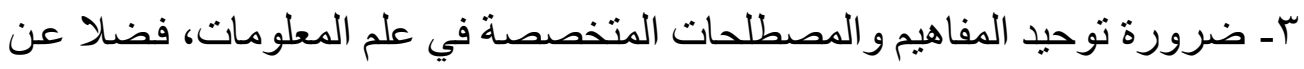

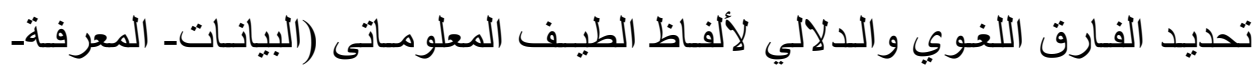
المعلوماتـ الحكمة) باعتبار ها محور در اسة علم المعلومات.

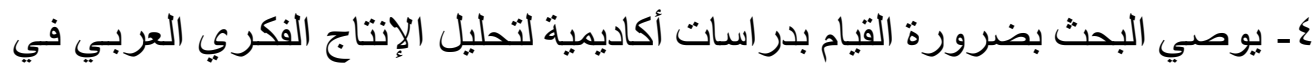

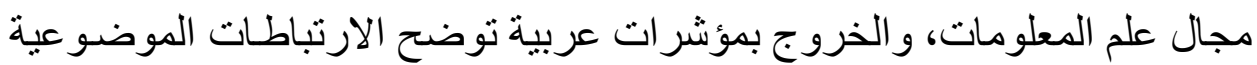
لعلم المعلومات. هـ العمـل على تكـوين بنـلك (مستودوع) معلومـات عربـي يتبنـاه فريـق متخـصص بمصطلحات ومفاهيم ومحاور علم المعلومات. 


\section{الهوامش والمراجع}

1-Machlup,F.,Mansfield,U." The Study of Information: Interdisciplinary Message" John Wiley: New York,1983.p6.

2-Zhang,Y." Principles of Information Science In Chinese" .- China :Fujian People Press, 1988.

3-Paisley, William." The Convergence of Communication and Information Science" .-Libraries and Information Science in The Electronic Age, 1989.

4- Borgman .Christine, Ronald Rice" The Convergence of Information Science and Communication: A bibliometric Analysis".- Journal of the American Society for Information Science, July 1992.

5-William,James" Information Science Definition and Scope".- Pittsburgh: Cathedral,1997.p.19.

6- Saracevic, Tefko." Interdisciplinary Nature of Information Science" .Ciencia da Infomacao,vol.24,no.1(1995).

7- Ingwersen,Peter.Information Retrieval Interaction.-London: Taylor Grahm,2002.

8- Holmes, Boyd Patterson. The Domain of Information Science with An Emphasis on Contributing Disciplines. Ph.D Program in Library and Information Science, Faculty of Information and Media Studies, The University of Western Ontario,London,Ontario( April 2002).

9- Smith, Linda C. " Inter disciplinary: Approach to Understanding

Library and Information Science As Interdisciplinary Field".- Conception of Library and Information Science. Pp 253-267.(1999).

10-Garcia,Cristiane L.\& Martha L.P. Valentin"Conceptual Maps As A tool for Knowledge Management at Universities".-Chile(2010)p1-4.

11- Yan, Xue-Shan." Information Science: Its Past, Present and Future".Information 2011.n.2.p.510-517.

12- Buckland, Michael" What Kind of Science Can Information Science Be".- Journal of Information Science and Technology ,vol.63,no.1 (2012). 
r ا ـ فيكرى، بر اين، و ألينا كامبل. علم المعلومات بين النظرية و التطبيق؛ ترجمة حشمت قاسم.-

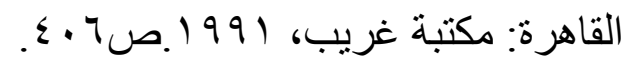

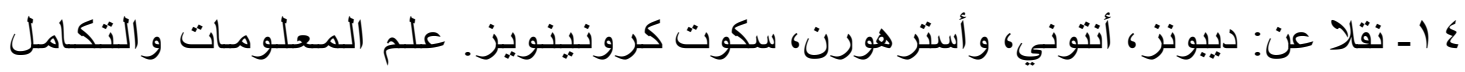

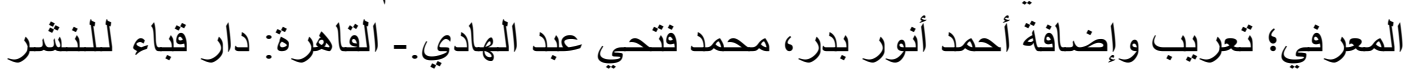

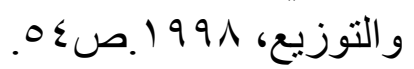

15- Hawkins ,Donald ,Larson Sigine" Information Science Abstracts: Tracking The Literature of Information Science" .- Journal of The American Society for Information Science and Technology,v.54,no.8 ( 2003) pp.771-781.

16-(a).Zins,Chain. "Conceptions of Information Science" .-Journal of The American Society for Information Science and Technology,v.58,no.3 ( 2007) pp.335-350.

(b) Zins, Chain. " Conceptual Approaches for Defining Data. Information, Knowledge" Journal of The American Society for Information Science and Technology,v.58,no.4( 2007) pp.479-493.

(c) Zins, Chain. " Knowledge Map of Information Science".- Journal of The American Society for Information Science and Technology ,v.58, no .4 ( 2007) pp.526-535.

(d) ) Zins, Chain" Classification Schemes of Information Science: Twenty- Eight Scholars Map The Field".- Journal of The American Society for Information Science and Technology, v.58,n.5 (2007)

17-" Knowledge Map of Information Science : Implications for The Future of The Field'.- Brazilian Journal of Information Science,vol.1,no.1(June 2007)pp.3-29.

18- Wang ,Bing" Information Science: The Territory and Relations to Computing Disciplines".- Journal of Library and Information Science,vol.35,no.1 ( April,2009) pp-4-22.

19- Sherif Kamel Shaheen.' A proposed Knowledge Map for Library, Archives and Information Science: From Academic Professional View Highlighting Cairo University '.- A paper Presented to The International Ninth Conference for The Department of Library, Archives and Information Science ,Annual Conference ,May,17-18(2012) Faculty of 
Arts, Cairo University.

20-Nguyen,San Hoang." Trends in Digital Library Research: A and Ontology Engineering Approach".-University Knowledge Mapping of Technology, Sydney (2013).

21-Cbango,Sylvain k." Information Science As A social Science ".-IR Information\&Research,vol. 10, no. ${ }^{r}($ September $r \cdot 1 \cdot)$. r Y Y حشمت قاسم. مدخل لدراسة المكتبات و علم المعلومات. طب، مزيدة ومنقحة._القاهرة: دار

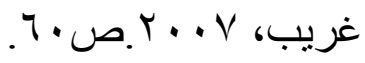

23-Steinerom,Jela " Interpreting Knowledge in Information Science".Knowledge Management ,1988,p3-7.

24- Orrico ,Evelyn. "Information Science. Popularization of Science and Social Memory: Dialog With Knowledge Organization".- Congress Isko-Spain,v.3,no.1( 2009) pp500-521.

25-Saracevic, Tefko " Information Science".- Journal of the American Society for Information Science,v.50,n.12(1999).p1052-1065.

26-Belkin,N."The Cognitive Viewpoint in Information Science".- Journal of Information Science,v.15,n.1(1990)pp.11-16.

27- Yan, Xue-Shan.Op.cit.p.514.

1 ץـ أحمد الكسيبي. "علم أم علوم للمعلومات: محاولة ضبط مجال علوم المعلومات".-مجلة

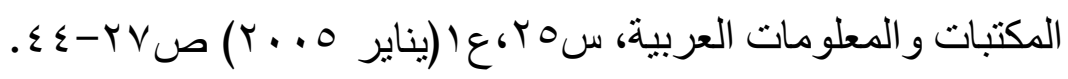

29- Wilson,T.D."On User Studies and Information Needs" .- Journal of Documentation,v.37,n.1(1981)pp.3-15.

30-Geographic Information Science. available from

http:www.wku.edu.gis( visited 3/12/2015)

31- Smith, Linda C. Op.cit.

32-Brooks,Bertram C." The Foundations of Information Science:

Philosophical Aspects" .- Journal of Information Science :Principle and

Practice,v.2,n.5(October 1980)pp125-133.

33-Tate,Vernon D." Introducing American Documentation: A quarterly 
Review Ideas, Techniques, Problems and Achievements" .-American Documentation Winter, v.1,n.1 (January 1950)p.3-7.

34- Holmes, Boyd Patterson. Op.cit.p.175.

35-Taylor,Robert S." The Information Science" .- Library Journal (November 1965).

36 -Cuadra,Carlos" Identifying Key Contributions to Information Science".-American Documentation.n.15(October 1965)p289-295.

37-Borko,Harold' Information Science: What is It?.- American Documentation,v.19,n.1(January 1968)p3-5.

38- Smith, Linda C. Op.cit.p.256.

39-Saunders.W.1 ' The Nature of Information Science" .- The Information Scientist,v.^,n. ${ }^{\prime}($ June $19 \vee \cdot) p p \circ \vee \_\vee \cdot$.

40-Brown,James J. "Information Science, Anew Disciplines? Edited by Antony Debonz and Arvid Larson. Information Science in Action: System Design, Boston :Martinus Nijhoff,1985.

41-Casper,Cheryl A.' Economics and Information Science' Edited by Antony Debonz and Arvid Larson. Information Science in Action: System Design .- Boston :Martinus Nijhoff,1985.

42- Holmes, Boyd Patterson. Op.cit.p.180.

43- Buckland, Michael"What Kind of Science Can Information Science Be" Op.cit.

44-Herner,Saul" Brief History of Information Science".- Journal of the American Society for Information Science, v.35,n.5 (1984).p157-165.

45- Holmes, Boyd Patterson. Op.cit.p.192.

46-Ibid.

47- Paisley, William .Op.cit.

48-Froelich,Thomas J." Challenges to Curriculum Development of Information Science".- Education for Information (December 1986) pp256-289.

49-Pertiz,Bluma" The Methods of Library Science Research: Some 
Results From A bibliometric Survey" .- Library Research,v.2,n.5(1980) pp.251-286.

•ــ نقلا عن: أحمد بدر.. التكامل المعرفي لعلم المعلومات و المكتبات. ـالقاهرة: دار

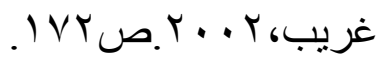

51-Chaudhry,Abdussattar" Information Science Curricula in Graduate Library School in Asia".- International Library Review,v.20,no.2(April 1988)pp.185-202.

52-Garrison,Guy" Challenges to Information Science Education".- Journal of the American Society for Information Science,v.39,n.5( September 1988).p362-366.

53-Garcia ,Cristiane L.\& Martha L.P. Op.cit.p.2.

54- Borgman, Christine, Ronald Rice. Op.cit.

55- Ingwersen,Peter. Op.cit.

56-Rayward,W.Boyd' The History and Historiography of Information Science: Some Reflections'.- Information Processing and Management,v.32,n.1(1996) pp5-17.

57- William, James. Op.cit.p.49.

58- Buckland, Michael. Op.cit.

59- Saracevic, Tefko " Information Science" Op.cit.

60- Smith, Linda C. Op.cit.p.26.

61-Summers, Ron' Information Science in 2010:Aloughborough University

View'.- Journal of the American Society for Information

Science,v.50,n.12( October 1999).p1153-1162.

62- Hawkins ,Donald ,Larson Sigine. Op.cit.p.275.

63- Orrico ,Evelyn.Op.cit.

ع اـ راجع. رضا محمد النجار "الطيف المعلوماتى المعرفي: دراسة استكثافية وتصور مقتر ح". ـ مجلة المكتبات و المعلومات العربية، س،ع (أكتوبر 17 ـ ب) قيد النشر.

65- Nguyen, San Hoang.Op.cit.p.275.

66-Ibid.p.7.

67-Loc.cit. 


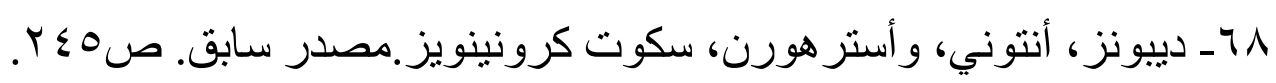

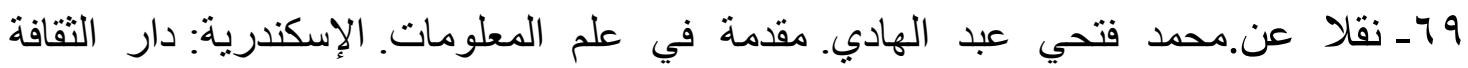

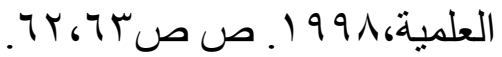

70- Saracevic, Tefko " Information Science" Op.cit.

71-Zins, Chain" Classification Schemes of Information Science: TwentyEight Scholars Map The Field"Op.cit.

72-Capurro,Rafael" Knowledge Map of Information Science".- Journal of the American Society for Information Science, v.58,n.5 (2007).

73- Zins, Chain" Classification Schemes of Information Science: TwentyEight Scholars Map The Field"Op.cit.

74-Ibid.

75-Hawkins ,Donald .op.cit.p.776.

76- Zins, Chain.Op.cit.

77- Hawkins ,Donald " Information Science Abstracts" .Op.cit.

78-Beghetol,Clare" Within, Among, Between : Three Faces Of Interdisciplinarity ".- Canadian Journal of Information and Library Science, v.20,n.2(July 1995).

79- Zins, Chain" Classification Schemes of Information Science: TwentyEight Scholars Map The Field "Op.cit.

80-Ibid.

81- Zins, Chain " Knowledge Map of Information Science".Op.cit. 82- Sherif Kamel Shaheen.Op.cit. 